\title{
Signature of small rings in the Raman spectra of normal and compressed amorphous silica: A combined classical and ab initio study.
}

\author{
Abdelali Rahmani \\ Département de Physique, Université MY Ismail, \\ Faculté des Sciences, BP 4010,50000 Meknès, Morocco \\ Magali Benoit \\ Laboratoire des Verres (UMR CNRS 5587), Université Montpellier II, 34095 Montpellier Cedex 5, France \\ Claude Benoit \\ Groupe de Dynamique des Phases Condensées (UMR CNRS 5581), \\ Université Montpellier II, 34095 Montpellier Cedex 5, France
}

(Dated: October 29, 2018)

\begin{abstract}
We calculate the parallel (VV) and perpendicular (VH) polarized Raman spectra of amorphous silica. Model $\mathrm{SiO}_{2}$ glasses, uncompressed and compressed, were generated by a combination of classical and $a b$ initio molecular-dynamics simulations and their dynamical matrices were computed within the framework of the density functional theory. The Raman scattering intensities were determined using the bond-polarizability model and a good agreement with experimental spectra was found. We confirm that the modes associated to the fourfold and threefold rings produce most of the Raman intensity of the $\mathrm{D}_{1}$ and $\mathrm{D}_{2}$ peaks, respectively, in the VV Raman spectra. Modifications of the Raman spectra upon compression are found to be in agreement with experimental data. We show that the modes associated to the fourfold rings still exist upon compression but do not produce a strong Raman intensity, whereas the ones associated to the threefold rings do. This result strongly suggests that the area under the $\mathrm{D}_{1}$ and $\mathrm{D}_{2}$ peaks is not directly proportional to the concentration of small rings in amorphous $\mathrm{SiO}_{2}$.

PACS numbers: 61.43.Fs,63.50.+x,78.30.-j,71.15.Pd
\end{abstract}

\section{INTRODUCTION}

Raman spectroscopy has provided a powerful tool to study the dynamical properties of amorphous materials. The interpretation of the vibrational spectra of vitreous silica $\left(\mathrm{a}-\mathrm{SiO}_{2}\right)$ has been of interest for many years and considerable progress has been made. Despite this fact, the origin of the $D_{1}$ and $D_{2}$ lines at $495 \mathrm{~cm}^{-1}$ and $606 \mathrm{~cm}^{-1}$, respectively, in the Raman spectrum is still not fully understood. In order to explain the frequencies of these bands, Galeener et al .1 .2 .3 .4 .5 has argued that $\mathrm{D}_{2}$ can be assigned to the breathing modes of a planar threefold ring, and $\mathrm{D}_{1}$ to that of a regular but slightly puckered fourfold ring within the continuous-random-network $(\mathrm{CRN})^{6.7}$. On the other hand and within the submicrocrystallite approach, Phillips ${ }^{8.9,10.11}$ has proposed that within the a-SiO${ }_{2}$ structure there exist two types of non-bridging oxygen (NBO) sites at the surface of the cluster, which can be associated to the structure responsible for the $\mathrm{D}_{1}$ and $\mathrm{D}_{2}$ defect lines. To date, much work has been done in the light of both models. Using a pair potential and the bond-polarizability (BP) model ${ }^{1.12}$, Murray and Ching 13 have calculated the Raman spectra for normal and compressed $\mathrm{SiO}_{2}$ glass models based on the CRN model with periodic boundary conditions. Their results generally reproduce the shapes of the bands present in experimental Raman spectra, particularly the $\mathrm{D}_{1}$ and $\mathrm{D}_{2}$ lines in contrast with the paracrystalline theory of $\mathrm{SiO}_{2}$. Moreover, the ring statistic analysis showed that there are no three or fourfold rings in their models. This means that the $\mathrm{D}_{1}$ and $\mathrm{D}_{2}$ lines are not strictly due to the threefold rings and fourfold rings as suggested by Galeener. To conciliate this later point of view and their work, Murray and Ching indicated that the Si-O-Si angles close to those found in the three and fourfold rings are responsible for these modes. More recently, using molecular-dynamics (MD) simulations and the BP model, Zotov et $a l^{14}$ have calculated the Raman spectra of a-SiO${ }_{2}$ models. The obtained VV Raman spectra were, generally, in good agreement with experiment but, despite the presence of three and fourfold rings, their models failed to reproduce the $\mathrm{D}_{1}$ and $\mathrm{D}_{2}$ peaks. Using a first-principles density functional approach, Umari et al ${ }^{15}$ have calculated the Raman intensities of $\alpha$-quartz by evaluating the variation of the polarizability tensors for finite displacements of the atoms. This work supports the use of the bond polarizability model for the calculation of the Raman intensities in a-SiO${ }_{2}$. By applying this method to an amorphous $\mathrm{SiO}_{2}$ sample containing a large concentration of threefold rings, they were able to relate the intensity of the $\mathrm{D}_{1}$ and $\mathrm{D}_{2}$ peaks to the concentration of four and threefold rings, respectively 16 . In a recent study, Benoit and Kob compared the vibrational properties of model $\mathrm{SiO}_{2}$ glasses generated by molecular-dynamics simulations using the effective force field by van Beest et al (BKS) 17 with the ones 
obtained if the BKS structure is relaxed using ab initio calculations ${ }^{18}$. It was found that this relaxation significantly improves the agreement of the density of states with the experimental result. Therefore it has become of interest to use the data of this approach to determine the Raman spectra of these systems.

In this work, we present the polarized Raman spectra of compressed and uncompressed a-SiO $\mathrm{S}_{2}$ samples prepared by combined classical and ab initio molecular dynamics simulations. Raman spectra were calculated using the bondpolarizability model and diagonalisation of the dynamical matrix, as obtained from the evaluation of the second derivatives of the total energy with respect to atomic displacements by taking finite differences of the atomic forces. In the following section, we describe the models used to compute the Raman spectra. Then in the third section we present the calculated spectra and a detailed analysis of the Raman signatures of the small rings. Finally the spectra are also calculated for compressed silica and a discussion in terms of the Raman signature of the rings is also given before the conclusion.

\section{COMPUTATIONAL METHOD}

The time averaged power flux of Raman scattered light in a given direction, with a frequency between $\omega_{f}$ and $\omega_{f}+d \omega_{f}$ in a solid angle $d \Omega$, is related to the differential scattering cross-section:

$$
\frac{d^{2} \sigma}{d \Omega d \omega_{f}}=\frac{1}{8 \pi^{2} c^{2}} \omega_{f}^{3} \omega_{i}(B(\omega)+1) \hbar \sum_{\alpha \beta \gamma \lambda} v_{\alpha} v_{\beta} H_{\alpha \gamma \beta \lambda}(\omega) w_{\gamma} w_{\lambda},
$$

where $\omega=\omega_{i}-\omega_{f}$ and

$$
H_{\alpha \gamma \beta \lambda}(\omega)=\sum_{j} a_{\alpha \gamma}^{\star}(j) a_{\beta \lambda}(j) \frac{1}{2 \omega_{j}}\left(\delta\left(\omega-\omega_{j}\right)-\delta\left(\omega+\omega_{j}\right)\right),
$$

with

$$
a_{\alpha \gamma}(j)=\sum_{n \delta} \frac{\pi_{\alpha \gamma, \delta}^{n}}{\sqrt{M_{n}}}<n \delta \mid j>,
$$

$\omega_{i}$ is the frequency of the incident light, $\vec{v}$ and $\vec{w}$ are the polarization unit vectors for scattered and incident light respectively, $B(\omega)$ is the Bose factor, $M_{n}$ the mass of the $n$th atom, $\omega_{j}$ and $\langle n \delta \mid j\rangle$ are respectively the frequency and the $(n \delta)$ component of the $j$ th mode. The Greek characters denote the Cartesian components (x,y,z). The coefficients $\pi_{\alpha \gamma, \delta}^{n}$ connect the polarization fluctuations to the atomic motions $\frac{19,20}{}$ and they are obtained by expanding the polarizability tensor $\tilde{\pi}^{n}$ in terms of atomic displacements $u_{\delta}^{n}$, with

$$
\pi_{\alpha \gamma, \delta}^{n}=\left.\sum_{m}\left(\frac{\partial \pi_{\alpha \gamma}^{m}}{\partial u_{\delta}^{n}}\right)\right|_{\left\{u_{\delta}^{n}\right\}=0} .
$$

In addition to these coefficients, the calculation of Raman intensities requires mode frequencies and eigenvectors: $\omega_{j}$ and $\langle n \delta \mid j\rangle$, obtained by solving the equation:

$$
\tilde{D}\left|j>=\omega_{j}^{2}\right| j>
$$

where $\tilde{D}$ is the dynamical matrix of the system, with the element $D_{\alpha \beta}(n m)=<n \alpha|\tilde{D}| m \beta>$. Each element of the dynamical matrix, $\tilde{D}$, is given by:

$$
D_{\alpha \beta}(n, m)=\frac{1}{\sqrt{M_{n} M_{m}}} \phi_{\alpha \beta}(n, m),
$$

with $\phi_{\alpha \beta}(n, m)$ being the force constants between atoms $n$ and $m$. In our calculations, the interactions are given by a first-principles approach.

If we assume that scattering can be described within the framework of the bond polarizability (BP) theory, the polarization is only modulated by nearest-neighbor bonds and the components of the induced polarizability tensor $\tilde{\pi}$ are given by ${ }^{12}$

$$
\pi_{\alpha \beta}(r)=\frac{1}{3}\left(\alpha_{l}+2 \alpha_{p}\right) \delta_{\alpha \beta}+\left(\alpha_{l}-\alpha_{p}\right)\left(\hat{r}_{\alpha} \hat{r}_{\beta}-\frac{1}{3} \delta_{\alpha \beta}\right)
$$


where $\hat{r}$ is the unit vector along vector $\vec{r}$ which connects the $n$ and $m$ atoms linked by the bond. The parameters $\alpha_{l}$ and $\alpha_{p}$ correspond to the longitudinal and perpendicular bond polarizability, respectively. Within this approach and in order to evaluate the derivatives, one assumes that the bond polarizability parameters are functions of the bond lengths $r$ only. The derivatives $\pi_{\alpha \beta, \gamma}^{n}$ are then given by ${ }^{12}$

$$
\pi_{\alpha \beta, \gamma}^{n}=\sum_{m} \frac{1}{3}\left(2 \alpha_{p}^{\prime}+\alpha_{l}^{\prime}\right) \delta_{\alpha \beta} \hat{r}_{\gamma}+\left(\alpha_{l}^{\prime}-\alpha_{p}^{\prime}\right)\left(\hat{r}_{\alpha} \hat{r}_{\beta}-\frac{1}{3} \delta_{\alpha \beta}\right) \hat{r}_{\gamma}+\frac{\left(\alpha_{l}-\alpha_{p}\right)}{r}\left(\delta_{\alpha \gamma} \hat{r}_{\beta}+\delta_{\beta \gamma} \hat{r}_{\alpha}-2 \hat{r}_{\alpha} \hat{r}_{\beta} \hat{r}_{\gamma}\right)
$$

where $\alpha^{\prime}=\left.(\partial \alpha / \partial r)\right|_{r=r_{0}}, r_{0}$ is the equilibrium distance.

In our a- $\mathrm{SiO}_{2}$ model, a single type of bond occurs ( $\left.\mathrm{Si}-\mathrm{O}\right)$ and the bond polarizability model is completely defined by three parameters: $\bar{\alpha}=\left(2 \alpha_{p}^{\prime}+\alpha_{l}^{\prime}\right), \bar{\beta}=\alpha_{l}^{\prime}-\alpha_{p}^{\prime}$ and $\bar{\gamma}=\left(\alpha_{l}-\alpha_{p}\right) / r$.

\section{RAMAN SCATTERING IN AMORPHOUS $\mathrm{SIO}_{2}$}

The amorphous $\mathrm{SiO}_{2}$ samples used in this study contain $26 \mathrm{SiO}_{2}$ units in a cubic box with periodic boundary conditions at the experimental density of $2.2 \mathrm{~g} . \mathrm{cm}^{-3}$. They were generated by molecular-dynamics simulations using the van Beest et al. force field 17 : Three well-equilibrated liquids at $3000 \mathrm{~K}$ were quenched to $300 \mathrm{~K}$ using three different quench rates $\left(7 \cdot 10^{10} \mathrm{~K} / \mathrm{s}(\mathrm{A}), 3 \cdot 10^{11} \mathrm{~K} / \mathrm{s}(\mathrm{B})\right.$ and $\left.5 \cdot 10^{12} \mathrm{~K} / \mathrm{s}(\mathrm{C})\right)$. The structures of the model samples were then refined using first-principles calculations of the Car-Parrinello type at $300 \mathrm{~K}$ using the CPMD code $\mathrm{e}^{21}$ (for the simulation details, see Ref $\frac{18}{2}$ ). After a relaxation of the atomic positions to $0 \mathrm{~K}$ in the density functional theory framework, the dynamical matrices of these samples were computed by evaluating the second derivatives of the $a b$ initio total energy with respect to the atomic displacements by taking the finite differences of the atomic forces. The vibrational frequencies and corresponding modes were obtained by diagonalisation of the dynamical matrices.

The structural characteristics of the three samples were first analyzed in terms of the pair correlation functions and of the static structure factors. All samples present a perfect tetrahedrally connected network and no noticeable sample specificities were found on such averaged quantities.

\section{A. Density of states}

The vibrational properties of a- $\mathrm{SiO}_{2}$ have been extensively investigated by many experimental and some theoretical means. In order to show the validity of the vibrational features of our model, we report, in Figure 1 the calculated effective neutron scattering cross section $G(\omega)=C(\omega) g(\omega)$, where $g(\omega)$ is the vibrational density of states and $C(\omega)$ was computed using the incoherent approximation, following $\operatorname{Ref} \underset{22}{2}$. The calculated $G(\omega)$ was obtained by averaging over the $G(\omega)$ of the three $\mathrm{SiO}_{2}$ samples A, B and C. The calculated $G(\omega)$ is compared to the experimental one ${ }^{23}$ and a good agreement between the two is observed. Shapes and positions of the principal peaks are well reproduced with a low-frequency band at $420 \mathrm{~cm}^{-1}$, an intermediate frequency band at $790 \mathrm{~cm}^{-1}$ and a double peak at 1050 $\mathrm{cm}^{-1}$ and $1195 \mathrm{~cm}^{-1}$ in the high-frequency region ${ }^{13,14.17}$. Note that the lack of a small peak at around $4 \mathrm{THz}$ in the experimental data is related to the insufficient experimental resolution 24 .

\section{B. Raman spectra}

The purpose of the present subsection is to present our calculation results for the polarized parallel (VV) and perpendicular $(\mathrm{VH})$ Raman spectra of different samples of $\mathrm{a}_{-} \mathrm{SiO}_{2}$. We assumed that scattering was produced by the BP mechanism. In all spectra, intensities represent the so-called reduced intensities, which are obtained by multiplying the experimentally measured spectrum with the correction factor $(\omega /(B(\omega)+1))$. In the VV configuration, both the incident and scattered polarizations are along the $\mathrm{z}$ axis and, for the $\mathrm{VH}$ configuration, the incident and scattered polarizations are along the $\mathrm{z}$ and $\mathrm{x}$ axis respectively. The intensities of the different spectra are normalized and, to make the comparison with the experimental results more realistic, we averaged over all sample orientations in the Raman spectra calculations.

Firstly the Raman spectra were calculated for normal density $\left(2.20 \mathrm{~g} / \mathrm{cm}^{3}\right)$ a-SiO $\mathrm{S}_{2}$ samples. The empirical parameters used in this study are those derived from the results of Umari et al $\frac{15}{5}$ for $\alpha$-quartz: $\bar{\alpha}=1.0, \bar{\beta}=0.25$ and $\bar{\gamma}=0.07$. 
The calculated Raman spectra (solid lines), which are obtained by an average over the three different a-SiO ${ }_{2}$ samples, are plotted together with the experimental result of Galeener ${ }^{2}$ in Figure 2 (dashed lines).

The calculated VV Raman spectrum (Figure 2(a)) is dominated by a lower band, around $500 \mathrm{~cm}^{-1}$ and reproduces the $\mathrm{D}_{1}=495 \mathrm{~cm}^{-1}$ and $\mathrm{D}_{2}=606 \mathrm{~cm}^{-1}$ peaks found in experimental spectra.11.25.26. The calculated $\mathrm{D}_{1}$ and $\mathrm{D}_{2}$ occur at $489 \mathrm{~cm}^{-1}$ and $614 \mathrm{~cm}^{-1}$, respectively. For these bands, the curve is very close in peak positions and qualitatively in peak shapes to the experimental curve. We note also that the bands at $436 \mathrm{~cm}^{-1}$ and $790 \mathrm{~cm}^{-1}$ are close to the experimental bands observed around $430 \mathrm{~cm}^{-1}$ and $800 \mathrm{~cm}^{-12.11 .25,26.27}$. In our calculation within the BP approximation, the double peak found experimentally in the high frequency region $\left(1100-1200 \mathrm{~cm}^{-1}\right) \mathrm{are}$ better reproduced than in previous works 13.14 . Concerning the VH spectrum, Figure 2(b), three major bands can be distinguished. The double peak in the high frequency region $\left(1100-1200 \mathrm{~cm}^{-1}\right)$ are well placed and the curve is, generally, close to the experiment. The lower band $\left(<500 \mathrm{~cm}^{-1}\right)$ and the intermediate one (around $\left.793 \mathrm{~cm}^{-1}\right)$ are positioned correctly but their intensities are too weak in comparison with the experimental lines.

In the VV Raman spectrum, the peaks around $430 \mathrm{~cm}^{-1}, 800 \mathrm{~cm}^{-1}$ and $1100-1200 \mathrm{~cm}^{-1}$ have been understood in terms of the vibrations of a CRN mode1.4.5. However the nature of the "defects" responsible for the $\mathrm{D}_{1}$ and $\mathrm{D}_{2}$ bands in the $\mathrm{VV}$ spectrum of $\mathrm{a}_{-} \mathrm{SiO}_{2}$ is still the subject of a theoretical controversy ${ }^{3.8 .9}$. As we have recalled above, according to Galeener ${ }^{1.2 .3 .4 .5}$, the $\mathrm{D}_{1}$ peak is due to the vibrational modes associated with oxygen atoms belonging to planar fourfold rings and the $\mathrm{D}_{2}$ peak to the ones associated with oxygens belonging to threefold rings within the CRN mode ${ }^{6.7}$. In contrast to this, Phillips ${ }^{8.9 .10,11}$ argued that these bands may be associated with skeletal surface $\mathrm{SiO}_{2}$ vibrational modes in the framework of paracrystalline theory. In the present work, the structural characteristics of the studied systems showed, on one hand, that they contain threefold and fourfold rings and on an another hand that, as the models of Murray and Ching 13 , none of them contain NBO sites or free surfaces. In Figure [3 we present the different ring size distributions of the three amorphous samples A, B and C. As it can be seen, the shapes of the ring size distributions are quite different for the three samples. Since no particular trend can be derived with respect to the quench rates used to generate these model structures, the differences found in the distributions are attributed to the statistics. However it is interesting to note that there is a significant amount of three and fourfold rings in all three samples. In previous molecular-dynamics simulations ${ }^{28}$, it has been shown that the concentration of small rings increases with an increasing quench rate. As a consequence, the concentration of small rings in our samples is certainly much larger than in real $\mathrm{SiO}_{2}$ samples. We find that the number of threefold rings varies from 1 in samples $\mathrm{A}$ and $\mathrm{C}$, to 2 in sample $\mathrm{B}$, and the number of fourfold rings are equal to 4 in sample A, to 3 in sample B and to 6 in sample C. Nevertheless, as shown in Figure 2 the VV Raman spectra of our models present both $\mathrm{D}_{1}$ and $\mathrm{D}_{2}$ peaks which means that the later may be correlated with the presence of the three and fourfold rings as argued by Galeener and excludes the Phillips point of view.

\section{Raman signature of the rings}

In order to clarify whether vibrational modes associated with the three and fourfold rings can be responsible for the $\mathrm{D}_{1}$ and $\mathrm{D}_{2}$ lines, we analyzed the Raman intensity due to these specific geometries. However the connection between a given geometry in the amorphous structure and the Raman intensity produced by it, is not straightforward at all.

In this perspective, we carried out an analysis on the three different samples individually. We first analyzed the modes that gave the strongest Raman activity in the $470-515 \mathrm{~cm}^{-1}$ range for the $\mathrm{D}_{1}$ line and in the $550-730 \mathrm{~cm}^{-1}$ range for the $\mathrm{D}_{2}$ line. The selection of these modes was done first by ordering the modes as a function of their Raman activity in the chosen frequency region. We then added together the activities of the most Raman-active modes until the sum reaches $80 \%$ of the total sum: Only the modes included in those $80 \%$ were subsequently studied.

Then, for the selected modes, we computed the localization entropy defined as:

$$
S_{j}=-\sum_{n \delta}|<n \delta| j>\left.\right|^{2} \times \frac{\ln \left(|<n \delta| j>\left.\right|^{2}\right)}{\ln (3 N)}
$$

where $\mid j>$ are the eigenmode components of mode $j$ and $\mid n \delta>$ are the $\delta$ eigenmode components of atom $n$. The above defined entropy is connected with the lack of information about the position of the $j$ th phonon and gives the same kind of information than the participation ratio. If the mode is perfectly localized, then the lack of information is minimum and only one of the $|\langle n \delta \mid j\rangle|^{2}$ is equal to one, which leads to $S_{j}=0$. On the other hand, if the $j$ th mode is completely delocalized, then $\mid\left\langle n \delta|j>|^{2}=1 / 3 N, \forall n \delta\right.$ and $S_{j}$ is maximum, i.e. equal to 1 . Here $S_{j}$ has been normalized to 1 for convenience, thus it is not a genuine entropy. Let us consider the case where the $j$ th mode 
is localized on a given ring composed of $N_{R}$ atoms. The value of $S_{j}$ would then be around:

$$
S_{j}^{R} \approx-\sum_{n \in \operatorname{Ring}} \frac{1}{3 N_{R}} \ln \left(\frac{1}{3 N_{R}}\right) / \ln (3 N)=\frac{\ln \left(3 N_{R}\right)}{\ln (3 N)}
$$

Thus if a mode is localized on all atoms in a threefold or a fourfold ring, the corresponding $S_{j}^{R}$ would be close to 0.529 or 0.582 , respectively. Table \ gives the localization entropies of the most Raman-active modes for every sample in the chosen frequency ranges. Note that $S_{j}$ gives an estimation of the localization of a mode but does not tell whether a mode is localized on a specific ring.

From table \it is clear that the most active Raman modes in the $470-515 \mathrm{~cm}^{-1}$ frequency range do not correspond to very localized modes since their localization entropies lie around 0.8 and are never smaller than 0.67 . The modes responsible of the $\mathrm{D}_{1}$ line can therefore not be considered as very localized modes. For $\mathrm{D}_{2}$, the situation is similar since the localization entropies lie also between 0.72 and 0.85 for the most intensive modes in the $550-730 \mathrm{~cm}^{-1}$ frequency range. Therefore this criterium does not appear to be useful in order to understand the nature of the modes responsible for the $\mathrm{D}_{1}$ and $\mathrm{D}_{2}$ lines.

We then tried to find other criteria that could help to determine whether these modes can be associated to the three and fourfold rings or not.

The first chosen criterium is based on vibrational considerations: For every mode and for each ring, we computed the following quantity

$$
A_{\text {Ring }}(j)=\sum_{n \in \text { Ring }}|<n \delta| j>\left.\right|^{2} .
$$

If the atomic displacements due to the considered mode are of similar amplitude for every atom, then the value of $A_{\text {Ring }}(j)$ would be equal to $3 \times 8 / 3 N$ for the fourfold rings and to $3 \times 6 / 3 N$ for the threefold rings since there are 8 or 6 atoms included, respectively. We therefore computed the quantity $P_{\operatorname{Ring}}(j)=A_{\operatorname{Ring}}(j) \times 3 N / 3 N_{R}$ where $N_{R}=8$ for the fourfold rings and $N_{R}=6$ for the threefold rings, in order to obtain an estimation of the participation of atoms belonging to a given ring, for a given mode. If the $j$ th mode is completely localized on a ring, one obtains the maximum value for $P_{\text {ring }}(j): P_{\text {Ring }}^{\max }(j)=9.75$ for the fourfold rings and $P_{\text {Ring }}^{\max }(j)=13$ for the threefold rings. Let us recall however that for a completely delocalized mode, $P_{\operatorname{Ring}}(j)$ is equal to one and that $P_{\operatorname{Ring}}(j)=0$ means that the considered ring is not concerned by the $j$ th mode.

The second chosen criterium is based on the contribution of a given mode and a given ring to the total Raman spectrum. This contribution is evaluated by computing what we name the "Raman ratio" which is defined in order to estimate the contribution of each ring to the Raman intensity of a given mode. Let us consider a given ring. The Raman intensity can be divided in three contributions by considering separately the atoms belonging to the ring and the other ones, in the following way:

$$
\begin{aligned}
a_{\alpha \gamma}(j) & =\sum_{n \notin \operatorname{Ring}} \frac{\pi_{\alpha \gamma, \delta}^{n}}{\sqrt{M_{n}}}<n \delta\left|j>+\sum_{n \in \operatorname{Ring}} \frac{\pi_{\alpha \gamma, \delta}^{n}}{\sqrt{M_{n}}}<n \delta\right| j> \\
& =a_{\alpha \gamma}^{\prime}(j)+a_{\alpha \gamma}^{\prime \prime}(j)
\end{aligned}
$$

For a given polarization (we omit the Greek indices), the contribution to the Raman scattering can be written as:

$$
\begin{aligned}
H_{\text {total }}(\omega)= & \sum_{j} a_{\alpha \gamma}^{\star}(j) a_{\beta \lambda}(j) \frac{1}{2 \omega_{j}}\left(\delta\left(\omega-\omega_{j}\right)-\delta\left(\omega+\omega_{j}\right)\right) \\
= & \sum_{j}\left[a_{\alpha \gamma}^{\prime}(j)+a_{\alpha \gamma}^{\prime \prime}(j)\right]^{\star}\left[a_{\beta \lambda}^{\prime}(j)+a_{\beta \lambda}^{\prime \prime}(j)\right] \frac{1}{2 \omega_{j}}\left(\delta\left(\omega-\omega_{j}\right)-\delta\left(\omega+\omega_{j}\right)\right) \\
= & \sum_{j}\left[a_{\alpha \gamma}^{\prime \star}(j) a_{\beta \lambda}^{\prime}(j)+a_{\alpha \gamma}^{\prime \prime \star}(j) a_{\beta \lambda}^{\prime \prime}(j)+\left\{a_{\alpha \gamma}^{\prime \star}(j) a_{\beta \lambda}^{\prime \prime}(j)+a_{\alpha \gamma}^{\prime \prime \star}(j) a_{\beta \lambda}^{\prime}(j)\right\}\right] \\
& \times \frac{1}{2 \omega_{j}}\left(\delta\left(\omega-\omega_{j}\right)-\delta\left(\omega+\omega_{j}\right)\right) \\
= & H_{\text {not } \operatorname{Ring}}(\omega)+H_{\text {Ring }}(\omega)+H_{\text {overlap }}(\omega)
\end{aligned}
$$

To obtain the contribution of the atoms belonging to a given ring to a selected mode $j_{0}$, we computed the integrated intensity of the spectrum, averaged over all possible sample orientations, in the chosen frequency range:

$$
V_{\text {Ring }}^{j_{0}}=V_{\text {total }}-V_{\text {not Ring }}^{j_{0}}
$$


with

$$
V_{\text {total }}=\int<H_{\text {total }}(\omega)>d \omega
$$

and

$$
V_{\text {not Ring }}^{j_{0}}=\int<H_{\text {not Ring }}^{j_{0}}(\omega)>d \omega
$$

where the $\langle\ldots\rangle$ denote the average over all possible orientations and $H_{\text {not Ring }}^{j_{0}}(\omega)$ has been obtained by setting to zero the $\langle n \delta| j_{0}>$ atomic components of the considered ring for the selected mode $j_{0}$. The integrals run over the frequency ranges corresponding to the $\mathrm{D}_{1}$ line or to the $\mathrm{D}_{2}$ line, depending on which type of rings we want to consider (fourfold or threefold).

We then needed a quantity that could be used in order to compare the contributions of different rings to the same mode. For this, we defined the relative Raman participation ratio as follows. The integrated Raman intensity of the spectrum, averaged over all possible orientations, has been computed without the contribution of mode $j_{0}$ :

$$
V_{\text {mode }}^{j_{0}}=V_{\text {total }}-V_{\text {not jo }}
$$

where

$$
V_{\text {not jo }}=\int<H_{\text {not jo }}(\omega)>d \omega
$$

and

$$
H_{\text {not } \mathrm{j}_{0}}(\omega)=\sum_{j \neq j_{0}} a_{\alpha \gamma}^{\star}(j) a_{\beta \lambda}(j) \frac{1}{2 \omega_{j}}\left(\delta\left(\omega-\omega_{j}\right)-\delta\left(\omega+\omega_{j}\right)\right) .
$$

The relative Raman participation ratio is then obtained by computing the quantity:

$$
\operatorname{Raman} \operatorname{ratio}\left(\mathrm{j}_{0}\right)=\frac{V_{\text {Ring }}^{j_{0}}}{V_{\text {mode }}^{j_{0}}} .
$$

The Raman ratio gives the relative participation of the atoms belonging to a given ring to the Raman intensity produced by the selected mode $j_{0}$.

If the atoms of the chosen ring do not participate to the mode $j_{0}$ then $V_{\text {Ring }}^{j_{0}}$ will be equal to zero and the Raman ratio as well. On the other hand, if only the atoms of the ring participate to the Raman scattering, then $V_{\text {Ring }}^{j_{0}}=V_{\text {total }}$ and the Raman ratio is maximum, i.e. equal to $V_{\text {total }} /\left(V_{\text {total }}-V_{\text {not jo }}\right)$. However, from the definition of $V_{\text {Ring }}^{j_{0}}$ (Eq. 19), one can see that the Raman ratio can be negative: This is due to the fact that the $H_{\text {overlap }}$ term can be negative with a magnitude larger than that of $H_{\text {Ring }}$ for the chosen ring. A negative $V_{\text {Ring }}^{j_{0}}$ would mean that there is a strong negative "coupling" between the atoms of the ring and the other atoms. A similar approach has already been used by Lazzeri et al. for the study of the ring contributions to the Raman spectra of crystalline silica phases and zeolites and has produced negative overlaps in these phases 29 . On the other hand, a large and positive Raman ratio would mean that the atoms of the ring participate to the mode but also that the coupling with the other atoms might be large and positive.

\section{1. $D_{1}$ line}

The results for the most Raman-active modes in the $470-515 \mathrm{~cm}^{-1}$ frequency range are presented in table $\amalg$ for the $\mathrm{A}, \mathrm{B}$ and $\mathrm{C}$ samples with the vibrational amplitudes $\left(P_{\text {Ring }}\right)$ on the left columns and the Raman ratio on the right columns.

If $P_{\text {Ring }}$ is larger than one for a given ring, the atoms belonging to this ring have larger displacements than the other atoms for the considered mode. From table $\amalg$ one can clearly see that the selected mode always gives rise to larger displacements on atoms belonging to one (or more than one) of the fourfold rings. As a consequence, one is tempted to "associate" Raman-active modes to specific rings: For instance, the $474 \mathrm{~cm}^{-1}$ mode in sample B generates 
large displacements on atoms belonging to ring 1 in that sample and the $507 \mathrm{~cm}^{-1}$ mode in sample A generates large displacements on atoms belonging to rings 1 and 2 in that sample.

The fact that some modes can be associated to several rings lead us to check whether these rings had common atoms. The result of this analysis is presented in table III Most of the time, when modes give large displacements on several rings, the later have indeed common atoms, but this is not always true. For instance, the $500 \mathrm{~cm}^{-1}$ mode in sample A generates large displacements on rings 2 and 3 , which do not have common atoms. This result indicates that there exist ring-like modes which concern more than one ring.

The Raman ratio defined above has been computed for the most Raman-active modes in samples A, B and C and for every fourfold ring in these systems. Results are presented on the right sides of table III for samples A, B and C separately. We first notice that the Raman ratio varies approximately from 1 to -1 and thus can be strongly negative. If we consider the largest positive Raman ratio, we note that they almost always correspond to the largest values of $P_{\text {Ring. }}$. By cross checking the largest terms in both the vibrational amplitudes $\left(P_{\text {Ring }}\right)$ and the Raman ratio, we can easily deduce that if the Raman ratio is large and positive, the atoms of the ring undergo larger displacements than the other atoms and therefore that the contribution of these atoms to the mode is important. On the other hand, if we consider the negative Raman ratio, we note that they almost always correspond to small - or close to $1-P_{\text {Ring }}$ values. This result is an indication that if the Raman ratio is negative, then the atoms of the ring do not participate much to the mode.

In order to illustrate the results presented in tables II we show examples of Raman spectra from which the contributions of the atoms in individual rings have been extracted. Let us consider the mode at $488 \mathrm{~cm}^{-1}$ of sample C. In figure 4 the total spectrum $\left(\mathrm{I}_{V V}\right)$ and the spectrum where this mode has been removed $\left(\mathrm{I}_{\text {mode }}\right)$ are depicted in bold lines. For this mode, the spectra for which the eigenmode components of atoms in rings 1, 3 and 6 have been set to zero, are shown in dashed lines ( $\mathrm{I}_{\text {Ring }}$ ). As it can be easily seen, for rings 1 and 6 , the $\mathrm{I}_{\text {mode }}$ and $\mathrm{I}_{\text {Ring }}$ almost exactly coincide ( $\mathrm{I}_{\text {mode }}-\mathrm{I}_{\text {Ring }}$ is almost zero) and the subtractions $\mathrm{I}_{V V}-\mathrm{I}_{\text {mode }}$ and $\mathrm{I}_{V V}-\mathrm{I}_{\text {Ring }}$ are identical. This situation corresponds to a Raman ratio close to one in table $\amalg$ and indicates that the atoms of rings 1 and 6 contribute significantly to the $488 \mathrm{~cm}^{-1}$ mode. On the opposite, for ring 3 , the $\mathrm{I}_{\text {Ring }}$ gives rise to a larger $\mathrm{D}_{1}$ peak than that of the total VV spectrum, leading to a negative $\mathrm{I}_{V V}$ - $\mathrm{I}_{\text {Ring }}$ contribution and very different $\mathrm{I}_{\text {mode }}$ and $\mathrm{I}_{\text {Ring }}$ spectra. This indicates that the atoms of ring 3 do not participate to the $488 \mathrm{~cm}^{-1}$ mode.

As a summary, our results suggest that the modes which produce more than $80 \%$ of the Raman activity in the frequency region of the $\mathrm{D}_{1}$ line can almost always be associated to the atoms belonging to one or more fourfold rings (i.e., the Raman ratio is larger than 0.7). Furthermore more than $70 \%$ of the atomic displacements due to these modes $\left(P_{\text {Ring }}\right)$ are located on atoms belonging to the fourfold rings. One exception can be found for the $496 \mathrm{~cm}^{-1}$ mode in sample $\mathrm{C}$, for which the Raman ratio is not larger than 0.5 for all rings.

\section{2. $D_{2}$ line}

Since the $\mathrm{D}_{2}$ line has been suggested to be due to modes involving the threefold rings, we analyzed the Raman modes in the corresponding frequency region with respect to atoms belonging to such rings. In the three $\mathrm{SiO}_{2}$ samples, the threefold rings are less numerous than the fourfold ones (1 in sample A, 2 in sample B and 1 in sample C), hence reducing the statistics in that case.

The results for the most Raman-active modes in the $550-730 \mathrm{~cm}^{-1}$ frequency range (corresponding to the $\mathrm{D}_{2}$ line in our spectrum) are presented in table IV for samples A, B and $\mathrm{C}$ with the vibrational amplitudes $\left(P_{\text {ring }}\right)$ on the left columns and the Raman ratio on the right columns. As for the $\mathrm{D}_{1}$ line, we can observe that there is a correlation between the largest $P_{\text {Ring }}$ values and the largest positive Raman ratio. We can also note that not all the Raman-active modes in the $\mathrm{D}_{2}$ line region correspond to modes associated to the threefold rings, whereas the contrary is true: All rings participate to, at least, one Raman-active mode in the $\mathrm{D}_{2}$ line region.

As for the $\mathrm{D}_{1}$ line, we illustrate the results presented in table IV by the Raman spectra depicted in figure 5 In this figure, we chose to show the Raman spectrum in which the mode of frequency $609 \mathrm{~cm}^{-1}$ in sample B has been removed ( $\mathrm{I}_{\text {mode }}$ ) together with the Raman spectra in which the eigenmode components of atoms belonging to the threefold rings have been set to zero ( $\mathrm{I}_{\text {Ring }}$ for rings 1 and 2 ). It is clear that if the eigenmode components of atoms in ring 2 are set to zero, the Raman spectrum is identical to the one obtained if the selected mode is removed, i.e. the resulting difference $I_{\text {Ring }}-I_{\text {mode }}$ (dotted line) is zero. On the opposite, the contribution of atoms of ring 1 to the $609 \mathrm{~cm}^{-1}$ mode is non-existent.

Recently Umari and Pasquarello 16 have deduced the proportion of oxygen atoms belonging to the threefold and fourfold rings in an experimental sample using a direct relation between the areas under the experimental and calculated $\mathrm{D}_{1}$ and $\mathrm{D}_{2}$ peaks, respectively. In view of the results presented in tables $\amalg$ and $1 \mathrm{v}$ such an approach seems a bit hazardous. Indeed, we have demonstrated that among the most Raman-active modes in the regions of the $\mathrm{D}_{1}$ 
and $\mathrm{D}_{2}$ lines (i.e. modes that produce more than $80 \%$ of the peaks), some can not be associated to modes involving atoms of a fourfold or a threefold ring. This result means that there is no proportionality relation between the area under the peaks and the proportion of threefold and fourfold rings in the $\mathrm{SiO}_{2}$ glass.

\section{RAMAN SCATTERING IN COMPRESSED AMORPHOUS $\mathrm{SIO}_{2}$}

\section{A. Generation of the compressed samples}

In order to mimic the effect of pressure, the box size of the amorphous sample $\mathrm{C}$ has been rescaled to three different sizes in successive steps. First, the box length and coordinates were rescaled from the experimental density of 2.20 $\mathrm{g} / \mathrm{cm}^{3}$ to a density of $2.40 \mathrm{~g} / \mathrm{cm}^{3}$ (sample C1) and a Car-Parrinello molecular-dynamics simulations of 1.9 ps was launched at $300 \mathrm{~K}$, using the CPMD code 21 . The entire procedure was repeated for two other densities: $2.67 \mathrm{~g} / \mathrm{cm}^{3}$ (sample C2) and $4.28 \mathrm{~g} / \mathrm{cm}^{3}$ (sample C3). For the sample at $2.67 \mathrm{~g} / \mathrm{cm}^{3}$, the initial coordinates were taken and rescaled from the final ones of the simulation performed on sample $\mathrm{C} 1$, and for the sample at $4.28 \mathrm{~g} / \mathrm{cm}^{3}$, the initial coordinates were taken and rescaled from the final ones of the simulation performed on sample C2. In this latter case, an important modification of the structure leading to an large increase of the ionic temperature was observed. Therefore during the first ps of the ab initio MD simulation, the ionic temperature has been constrained to stay at $300 \mathrm{~K}$. This constraint was then released for the rest of the ab initio MD simulation on sample C3. In order to achieve good convergence for the calculation of the pressures in samples C1, C2 and C3, higher energy cutoffs would be required. We estimated that this information was not worth the computational effort and obtained the pressures from the volume to pressure conversion using the experimental equation of state of $\mathrm{a}_{-} \mathrm{SiO}_{2}{ }^{30}$. The pressures of our samples are thus evaluated to $\approx 3 \mathrm{GPa}$ for sample $\mathrm{C} 1, \approx 7 \mathrm{GPa}$ for sample $\mathrm{C} 2$ and $\approx 34 \mathrm{GPa}$ for sample $\mathrm{C} 3$.

For samples $\mathrm{C} 1$ and $\mathrm{C} 2$, we observe no modifications of the network topology. The observed structural modifications only concern the shift of the Si-O-Si angle distributions towards smaller angles (Figure 6) and no changes in the Si-O bond lengths and in the ring statistics are noticed. In contrast to this, the structure of sample C3 is very different from the ones of sample C, C1 and C2: The tetrahedral network is destroyed and replaced by a mixing of four, five and sixfold-coordinated silicon atoms connected by corners and/or edges, and threefold-coordinated oxygen atoms. These coordination changes explain the very different $\mathrm{Si}-\mathrm{O}-\mathrm{Si}$ and $\mathrm{O}-\mathrm{Si}-\mathrm{O}$ angular distributions observed in Figure 6

At the end of these $a b$ initio molecular-dynamics simulations, the atomic coordinates were relaxed to $0 \mathrm{~K}$ and the dynamical matrices were computed as described in section [III For every sample, we then obtained the vibrational frequencies and the corresponding modes by a diagonalisation of the dynamical matrices. The vibrational densities of states of sample $\mathrm{C}$ and of the three compressed samples C1, C2 and C3 are depicted in Figure 7 As pressure is increased from $\mathrm{C}$ to $\mathrm{C} 2$, the double peak in the high frequency region disappears and the peaks at $\sim 600 \mathrm{~cm}^{-1}$ and $\sim 800 \mathrm{~cm}^{-1}$ are shifted to higher wavenumbers. One can also notice a decrease of the peak intensity at $\sim 400 \mathrm{~cm}^{-1}$. On the other hand, the vibrational density of states of sample C3 exhibits very different features which reflect the changes in the structure: No clear gap can be seen in the broad peak going from $\sim 100 \mathrm{~cm}^{-1}$ up to $1300 \mathrm{~cm}^{-1}$.

\section{B. Raman spectra and signature of the rings}

In Figure 8, the VV (left panel) and VH (right panel) Raman spectra of the compressed samples C1, C2 and C3 are compared to that of sample C. Firstly, we note that the VV and VH spectra of sample C3 are very different compared to that of samples $\mathrm{C}, \mathrm{C} 1$ and $\mathrm{C} 2$, which is due to its very different density of states and structure. For the slightly compressed samples $(\mathrm{C} 1$ and $\mathrm{C} 2)$ the main band and the $\mathrm{D}_{1}$ line in the VV spectra merge into a sharp main peak. The intensity of this peak increases with increasing density and moves to higher wavenumbers. The increasing sharpness of the band around $\mathrm{D}_{1}$ with increasing density could be attributed to the shift to lower angle and the increasing sharpness of the Si-O-Si angle distribution shown in Figure [ In contrast with this behavior, the $\mathrm{D}_{2}$ line intensity does not increase with increasing density, however its position slightly shifts towards higher wavenumbers. One can also note that all the bands lower than $900 \mathrm{~cm}^{-1}$ clearly shift to higher wavenumbers. On the opposite, in the high frequency region, we observe that the double peak slightly shifts to lower wavenumbers. Overall these behaviors have been observed experimentally ${ }^{25.30}$ and reproduced by other numerical studies ${ }^{13}$. For the VH spectra, we observe that the principal bands shift to higher wavenumbers except for the largest peak of the double peak in the high frequency region.

In order to show the effect of compression on the ring contributions, we have evaluated the localization entropies, the vibrational amplitudes $P_{\text {Ring }}$ and the Raman ratio as defined in section $1 \mathrm{CC}$ for all rings in samples $\mathrm{C} 1$ and $\mathrm{C} 2$. The sample C3 was not studied in that respect since the tetrahedral network is damaged in that sample. The results 
are presented in table $\nabla$ for the entropies and in table $\nabla]$ and table $\nabla I]$ for the $P_{\text {Ring }}$ values and the Raman ratio in the frequency regions of the $\mathrm{D}_{1}$ and $\mathrm{D}_{2}$ lines, respectively.

The results presented in table $\mathrm{V}$ show that the modes contributing to the sharp line around $500 \mathrm{~cm}^{-1}$ are less numerous in the compressed samples $\mathrm{C} 1$ and $\mathrm{C} 2$ than in sample C. For samples $\mathrm{C} 1$ and $\mathrm{C} 2$, the frequency range in which these modes have been sought for was modified to take into account the frequency shift of the peaks. These frequency regions have been set to $490-540 \mathrm{~cm}^{-1}$ for sample $\mathrm{C} 1$ and to $505-585 \mathrm{~cm}^{-1}$ for sample $\mathrm{C} 2$. It should be noted that the intense sharp peak at $540 \mathrm{~cm}^{-1}$ in sample C2 is due to only two modes that produce $80 \%$ of the total Raman intensity. However, the entropies of these modes are not much different from the ones of the modes responsible of the $\mathrm{D}_{1}$ line in the uncompressed samples. A similar conclusion on the localization entropy can be given for what concerns the most Raman-active modes in the frequency region around the $\mathrm{D}_{2}$ line $\left(605-770 \mathrm{~cm}^{-1}\right)$. Note however that there are more Raman-active modes in this region than in the $\mathrm{D}_{2}$ region of the uncompressed sample $\mathrm{C}$.

The vibrational amplitudes $\left(P_{\text {Ring }}\right)$ and the Raman ratio (see definitions in section IIC) were then evaluated for the selected modes in the frequency regions of interest. The results for the modes in the 490-540 $\mathrm{cm}^{-1}$ and $505-585$ $\mathrm{cm}^{-1}$ frequency regions are presented in table VI The mode at $503 \mathrm{~cm}^{-1}$ in sample $\mathrm{C} 1$ is clearly the same mode than

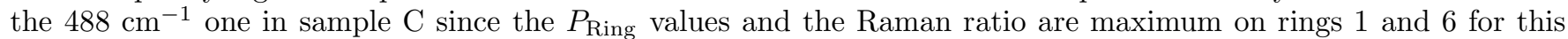
mode. The mode at $512 \mathrm{~cm}^{-1}$ in sample $\mathrm{C} 1$ could also be related to the $496 \mathrm{~cm}^{-1}$ mode in sample $\mathrm{C}$ if one considers the value of $P_{\text {Ring }}$ which is maximum on ring 5. Upon compression these two modes have been shifted of roughly 15 $\mathrm{cm}^{-1}$. However, all the other modes that were associated to one or two rings in sample $\mathrm{C}$, have disappeared in sample $\mathrm{C} 1$ and, upon further compression in sample C2, even the modes that were still present in sample C1 vanished. For sample $\mathrm{C} 2$, the remaining modes in the $505-585 \mathrm{~cm}^{-1}$ frequency range do not present large values of $P_{\text {Ring }}$ or of the Raman ratio: This indicates that the Raman-active modes in this frequency region can not be associated to motions of atoms belonging to a fourfold ring. Since the same rings of sample C still exist in sample C2, this result means that the compression induced a structural modification of the rings and of their environment that produced the extinction of the ring-like modes in the Raman spectra. When sample $\mathrm{C}$ is compressed into $\mathrm{C} 1$ and $\mathrm{C} 2$, the network connections (and thus the rings) do not change with increasing density but only the angles and relative distances between atoms do. The changes in the Raman spectra are therefore not due to a different proportion of rings but only to changes in the structure of the rings, mainly the decrease of the Si-O-Si angles. A more detailed analysis showed that the ring-like modes still exist in this frequency range (i.e. there are modes for which $P_{\text {Ring }}$ is maximum for a given fourfold ring) but their Raman activities are much smaller, if not zero.

The effect of compression seems to be a little different for the modes in the frequency region corresponding to the

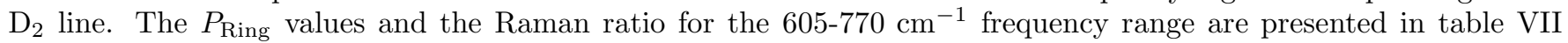
for the compressed samples $\mathrm{C} 1$ and $\mathrm{C} 2$. In both samples, one can see that there is always one mode being clearly associated to the threefold ring: The $646 \mathrm{~cm}^{-1}$ mode in sample $\mathrm{C} 1$ and the $664 \mathrm{~cm}^{-1}$ one in sample $\mathrm{C} 2$. This result indicates that the mode at $619 \mathrm{~cm}^{-1}$ in sample $\mathrm{C}$ is still present in samples $\mathrm{C} 1$ and $\mathrm{C} 2$ but is shifted of approximately $28 \mathrm{~cm}^{-1}$ and $45 \mathrm{~cm}^{-1}$, respectively, upon compression. The ring-like mode associated to the threefold ring remains therefore Raman-active upon larger compression than the ones associated to the fourfold rings. This is certainly due to the fact that the $\mathrm{Si}-\mathrm{O}-\mathrm{Si}$ angles in the threefold rings have less possibility to change than in the fourfold rings. Indeed we checked that the Si-O-Si angles of the threefold ring in sample $\mathrm{C}, \mathrm{C} 1$ and $\mathrm{C} 2$ change by less than $3^{\circ}$ upon compression, whereas changes of more than $20^{\circ}$ were noticed in the case of the Si-O-Si angles of the fourfold rings.

\section{CONCLUSION}

We have presented results for VV and VH Raman spectra for uncompressed and compressed amorphous silica models generated by ab initio molecular-dynamics simulations. To model scattering in these materials we have considered the bond-polarizability mechanism. This mechanism gives rise to VV and VH spectra in good agreement with experimental data in shapes and peak positions. Analysis of the VV partial Raman spectra confirms that the $\mathrm{D}_{1}$ and $\mathrm{D}_{2}$ peaks are due to the presence of four and threefold rings respectively, as suggested by Galeener. The association of ring-like modes to the peaks was done by using two approaches, one based on the atomic motions of the atoms belonging to the ring and the other one based on the calculation of the partial Raman spectra for atoms belonging to the ring. Both approaches give qualitatively the same results and show that not all rings necessarily produce a strong Raman activity.

The Raman spectra obtained for compressed samples were also computed and are in very good agreement with experimental results by Hemley et al ${ }^{30}$ for densified samples. As long as the tetrahedral network is maintained, we find that the Raman peak around $500 \mathrm{~cm}^{-1}$ is not necessarily due to modes associated to the fourfold rings although these rings are still present in the glass sample. However the $\mathrm{D}_{2}$ line still exists upon compression and can still be associated to the threefold rings. 
These results suggest that (i) there exist collective ring-like modes (involving several rings), (ii) the presence of the $\mathrm{D}_{1}$ and $\mathrm{D}_{2}$ lines can be associated to the presence of fourfold and threefold rings in the glass sample, (iii) the absence of the $\mathrm{D}_{1}$ and $\mathrm{D}_{2}$ lines does not mean that there are no fourfold and threefold rings in the sample, (iv) the area under the $\mathrm{D}_{1}$ and the $\mathrm{D}_{2}$ peaks are not simply proportional to the concentration of small rings in the $\mathrm{SiO}_{2}$ sample, as it has been previously proposed.

As a conclusion, we were able to show that a combination of classical models (the molecular-dynamics simulations for the generation of the amorphous samples and the scattering models) and of first-principles calculations (the ab initio computation of the dynamical matrices) can be used to successfully compute the Raman spectra of amorphous silica and to extract detailed information about the Raman signature of structural units such as small rings.

\section{Acknowledgements}

We thank Walter Kob for very helpful discussions and a careful reading of the manuscript. The computations were performed at CINES (Montpellier, France) on IBM SP3 computer. The work was supported by a CNRSFrance/CNCPRST-Morocco agreement.

1 F.L. Galeener, Phys. Rev. B 19, 4292 (1979).

${ }^{2}$ F.L. Galeener, Solid State Commun. 44, 1037 (1982).

3 F.L. Galeener, R.A Barrio, E. Martinez, and R.J. Elliott, Phys. Rev. Lett. 53, 2429 (1984).

${ }^{4}$ R.A Barrio, F.L. Galeener, and E. Martinez, Phys. Rev. Lett. 52, 1786 (1984).

5 R. M. Martin and F.L. Galeener, Phys. Rev. B 23, 3071 (1981).

6 W. H. Zachariasen, J. Am. Chem. Soc. 54, 3841(1932).

7 R. J. Bell and P. J. Dean, Phil. Mag. 25, 1381(1972).

8 J. C. Phillips, in Solid State Physics, edited by Ehrenreich, F. Seitz, and D. Turnbull (Academic, New York, 1982), vol. 37, p.93.

9 J. C. Phillips, J. Non-Cryst. Solids 63, 347 (1984).

10 J. C. Phillips, Phys. Rev. B 32, 5350 (1985).

11 J. C. Phillips, Phys. Rev. B 33, 4443 (1986).

12 R. J. Bell, Methods in computational Physics (Academic, New York, 1976), 15, p.215.

13 R. A. Murray, and W. Y. Ching, Phys. Rev. B 39, 1320 (1989).

14 N. Zotov, I. Ebbsjö, D. Timpel, and H. Keppler, Phys. Rev. B 60, 6383 (1987).

15 P. Umari, A. Pasquarello, and A. Dal Corso, Phys. Rev. B 63, 94305 (2001).

16 P. Umari and A. Pasquarello, Physica B 316-317, 572 (2002).

17 B. W. H. van Beest, G. J. Kramer, and R. A. van Santen, Phys. Rev. Lett. 64, 1955 (1990).

18 M. Benoit and W. Kob, Europhys. Lett. 60, 269 (2002).

19 A. Rahmani, J.-L. Sauvajol, S. Rols and C. Benoit, Phys. Rev. B 66, 125404 (2002).

20 G. Viliani et al., Phys. Rev. B 52, 3346 (1995); Phys.: Condens. Matter 9, 2149 (1997).

21 CPMD V3.4 Copyright IBM Corp. 1990-2001, Copyright MPI für Festkörperforschung Stuttgart 1997-2001.

22 S.N. Taraskin and S.R. Elliott, Phys. Rev. B 55, 117 (1997).

23 J.M. Carpenter and D.L. Price, Phys. Rev. Lett. 54, 441 (1985).

24 A. Wischnewski, U. Buchenau, A. J. Dianoux, W. A. Kamitakahara, and J. L. Zarestky, Phys. Rev. B 57, 2663 (1998).

25 P. McMillan, B. Piriou, and R. Couty, J. Chem. Phys. 81, 4234 (1984).

26 R. H. Stolen and G. E. Walrafen, J. Chem. Phys. 64, 2623 (1976).

27 A.E. Geissberger and F.L. Galeener, Phys. Rev. B 28, 3266 (1983).

28 K. Vollmayr, W. Kob and K. Binder, Phys. Rev. B 54, 15808 (1996).

29 M. Lazzeri and F. Mauri, Phys. Rev. Lett. 90, 036401 (2003).

30 R. J. Hemley, H. K. Mao, P. M. Bell, and B. O. Mysen, Phys. Rev. Lett. 57, 747 (1986). 
TABLE I: Frequency, Raman intensity and localisation entropy for the most Raman-active modes in the $470-515 \mathrm{~cm}^{-1}$ frequency range $\left(\mathrm{D}_{1}\right.$ line) and in the $550-730 \mathrm{~cm}^{-1}$ frequency range $\left(\mathrm{D}_{2}\right.$ line) for the three $\mathrm{SiO}_{2}$ samples $\mathrm{A}, \mathrm{B}$ and $\mathrm{C}$.

\begin{tabular}{|c|c|c||c|c|c||c|c|c|}
\hline \multicolumn{3}{|c||}{ sample A } & \multicolumn{3}{c||}{ sample B } & \multicolumn{3}{c|}{ sample C } \\
\hline $\begin{array}{c}\text { frequency } \\
\left(\mathrm{cm}^{-1}\right)\end{array}$ & $\begin{array}{c}\text { Raman } \\
\text { intensity } \\
\text { (a.u.) }\end{array}$ & $\begin{array}{c}\text { localisation } \\
\text { entropy }\end{array}$ & $\begin{array}{c}\text { frequency } \\
\left(\mathrm{cm}^{-1}\right)\end{array}$ & $\begin{array}{c}\text { Raman } \\
\text { intensity } \\
\text { (a.u.) }\end{array}$ & $\begin{array}{c}\text { localisation } \\
\text { entropy }\end{array}$ & $\begin{array}{c}\text { frequency } \\
\left(\mathrm{cm}^{-1}\right)\end{array}$ & $\begin{array}{c}\text { Raman } \\
\text { intensity } \\
\text { (a.u. })\end{array}$ & $\begin{array}{c}\text { localisation } \\
\text { entropy }\end{array}$ \\
\hline 507 & $5.76 \cdot 10^{-3}$ & 0.801 & 498 & $5.32 \cdot 10^{-3}$ & 0.806 & 406 & $7.16 \cdot 10^{-3}$ & 0.831 \\
500 & $4.86 \cdot 10^{-3}$ & 0.804 & 474 & $4.38 \cdot 10^{-3}$ & 0.678 & 488 & $6.76 \cdot 10^{-3}$ & 0.777 \\
474 & $4.42 \cdot 10^{-3}$ & 0.757 & 512 & $4.37 \cdot 10^{-3}$ & 0.811 & 486 & $5.36 \cdot 10^{-3}$ & 0.804 \\
& & & 489 & $2.09 \cdot 10^{-3}$ & 0.836 & 520 & $3.96 \cdot 10^{-3}$ & 0.823 \\
& & & 521 & $1.87 \cdot 10^{-3}$ & 0.847 & 501 & $2.20 \cdot 10^{-3}$ & 0.872 \\
\hline
\end{tabular}

\begin{tabular}{|c|c|c||c|c|c||c|c|c|}
\hline \multicolumn{3}{|c||}{ Dample A } & \multicolumn{3}{c||}{ sample B } & \multicolumn{3}{c|}{ sample C } \\
\hline $\begin{array}{c}\text { frequency } \\
\left(\mathrm{cm}^{-1}\right)\end{array}$ & $\begin{array}{c}\text { Raman } \\
\text { intensity } \\
\text { (a.u. })\end{array}$ & $\begin{array}{c}\text { localisation } \\
\text { entropy }\end{array}$ & $\begin{array}{c}\text { frequency } \\
\left(\mathrm{cm}^{-1}\right)\end{array}$ & $\begin{array}{c}\text { Raman } \\
\text { intensity } \\
(\text { a.u. })\end{array}$ & $\begin{array}{c}\text { localisation } \\
\text { entropy }\end{array}$ & $\begin{array}{c}\text { frequency } \\
\left(\mathrm{cm}^{-1}\right)\end{array}$ & $\begin{array}{c}\text { Raman } \\
\text { intensity } \\
\text { (a.u. })\end{array}$ & $\begin{array}{c}\text { localisation } \\
\text { entropy }\end{array}$ \\
\hline 634 & $7.61 \cdot 10^{-3}$ & 0.81 & 602 & $1.05 \cdot 10^{-2}$ & 0.82 & 619 & $1.53 \cdot 10^{-2}$ & 0.75 \\
661 & $2.88 \cdot 10^{-3}$ & 0.82 & 609 & $7.28 \cdot 10^{-3}$ & 0.73 & 652 & $2.82 \cdot 10^{-3}$ & 0.85 \\
606 & $1.68 \cdot 10^{-3}$ & 0.82 & 639 & $6.91 \cdot 10^{-3}$ & 0.72 & 665 & $2.12 \cdot 10^{-3}$ & 0.79 \\
639 & $1.64 \cdot 10^{-3}$ & 0.85 & 596 & $5.51 \cdot 10^{-3}$ & 0.83 & & & \\
\hline
\end{tabular}

TABLE II: $P_{\text {Ring }}$ and Raman ratio (see text for definitions) for the most Raman-active modes in the $470-515 \mathrm{~cm}^{-1}$ frequency range for the three $\mathrm{SiO}_{2}$ samples $\mathrm{A}, \mathrm{B}$ and C.

\begin{tabular}{|c|c|c|c|c|c|c|c|c|}
\hline \multicolumn{9}{|c|}{ Sample A } \\
\hline $\begin{array}{c}\text { Frequency } \\
\left(\mathrm{cm}^{-1}\right)\end{array}$ & ring 1 & $\begin{array}{r}P_{1} \\
\text { |ring } 2\end{array}$ & $\begin{array}{l}\text { Ring } \\
\mid \text { ring } 3 \mid\end{array}$ & ring 4 & ring 1 & $\begin{array}{l}\text { Rama } \\
\text { ring } 2\end{array}$ & $\begin{array}{l}\text { ratio } \\
\text { |ring } 3\end{array}$ & |ring 4 \\
\hline 507 & 3.16 & 2.35 & 0.76 & 1.35 & 0.83 & 0.70 & -0.32 & 0.42 \\
\hline 500 & 1.11 & 2.60 & 2.63 & 0.40 & 0.14 & 0.59 & 0.76 & 0.21 \\
\hline 474 & 0.30 & 0.41 & 0.44 & 1.96 & 0.08 & 0.15 & 0.16 & 0.33 \\
\hline
\end{tabular}

Sample B

\begin{tabular}{|c||c|c|c||c|c|c|}
\hline \multicolumn{1}{|c||}{$\begin{array}{c}\text { Frequency } \\
\left(\mathrm{cm}^{-1}\right)\end{array}$} & ring 1 & ring 2 & ring 3 & ring 1 & ring 2 & ring 3 \\
\hline 498 & 0.39 & 0.63 & 3.81 & 0.04 & 0.23 & 0.89 \\
474 & 5.24 & 0.35 & 0.16 & 0.95 & -0.04 & $-510^{-3}$ \\
513 & 0.47 & 2.99 & 0.85 & 0.19 & 0.89 & -0.43 \\
489 & 0.61 & 1.23 & 1.31 & 0.11 & -0.52 & 0.79 \\
\hline
\end{tabular}

Sample C

\begin{tabular}{|c||c|c|c|c|c|c||c|c|c|c|c|c|}
\hline \multicolumn{1}{|c|}{$\begin{array}{c}\text { Frequency } \\
\left(\mathrm{cm}^{-1}\right)\end{array}$} & ring 1 & ring 2 & ring 3 & ring 4 & ring 5 & ring 6 & ring 1 & ring 2 & ring 3 & ring 4 & ring 5 & ring 6 \\
\hline 496 & 0.50 & 0.80 & 0.98 & 1.12 & 2.62 & 0.53 & 0.22 & 0.09 & -0.08 & 0.18 & 0.49 & 0.23 \\
488 & 3.99 & 0.18 & 0.76 & 0.67 & 0.53 & 3.93 & 0.91 & 0.18 & -0.33 & -0.29 & 0.05 & 0.89 \\
486 & 0.79 & 1.59 & 2.32 & 2.55 & 1.55 & 0.61 & 0.46 & 0.66 & 0.68 & 0.73 & -0.52 & 0.43 \\
520 & 0.67 & 1.37 & 2.88 & 1.17 & 2.48 & 0.32 & 0.30 & -0.83 & 0.99 & 0.56 & 0.90 & 0.23 \\
\hline
\end{tabular}


TABLE III: Number of common atoms in the fourfold rings of samples A, B, C, C1 and C2.

\begin{tabular}{|c|c|c|c|c|c|c|c|c|c|c|c|c|c|}
\hline & ring 1 & $\begin{array}{l}\text { San } \\
\text { ring }\end{array}$ & $\begin{array}{l}\text { le } \mathrm{A} \\
\text { ring }\end{array}$ & ring 4 & ring & $\begin{array}{l}\text { Sample } \\
1 \text { ring }\end{array}$ & $\begin{array}{l}\mathrm{B} \\
2 \operatorname{ring} 3\end{array}$ & ring 1 & $\begin{array}{r}\text { Sam } \\
\text { ring } 2\end{array}$ & $\begin{array}{r}\text { ples } C \text {, } \\
\text { ring } 3\end{array}$ & $\begin{array}{l}\mathrm{C} 1 \mathrm{ar} \\
\text { ring } 4\end{array}$ & $\begin{array}{l}\text { nd } \mathrm{C} 2 \\
4 \text { ring } 5\end{array}$ & ring 6 \\
\hline ring 1 & - & 3 & 0 & 0 & - & 1 & 0 & - & 0 & 0 & 0 & 0 & 3 \\
\hline ring 2 & 3 & - & 0 & 0 & 1 & - & 0 & 0 & - & 0 & 0 & 0 & 0 \\
\hline ring 3 & 0 & 0 & - & 0 & 0 & 0 & - & 0 & 0 & - & 3 & 3 & 0 \\
\hline ring 4 & 0 & 0 & 0 & - & & & & 0 & 0 & 3 & - & 1 & 0 \\
\hline ring 5 & & & & & & & & 0 & 0 & 3 & 1 & - & 0 \\
\hline ring 6 & & & & & & & & 3 & 0 & 0 & 0 & 0 & - \\
\hline
\end{tabular}

TABLE IV: $P_{\text {Ring }}$ and Raman ratio (see text for definitions) for the most Raman-active modes in the $550-730 \mathrm{~cm}^{-1}$ frequency range for the three $\mathrm{SiO}_{2}$ samples $\mathrm{A}, \mathrm{B}$ and C.

Sample A

\begin{tabular}{|c||c||c|}
\hline $\begin{array}{c}\text { Frequency } \\
\left(\mathrm{cm}^{-1}\right)\end{array}$ & $\begin{array}{c}P_{\text {Ring }} \\
\text { ring 1 }\end{array}$ & $\begin{array}{c}\text { Raman ratio } \\
\text { ring 1 }\end{array}$ \\
\hline 634 & 3.33 & 0.83 \\
661 & 3.16 & 0.97 \\
606 & 0.69 & 0.24 \\
639 & 1.71 & 0.83 \\
\hline
\end{tabular}

Sample B

\begin{tabular}{|c||c|c||c|c|}
\hline \multicolumn{1}{|c||}{$\begin{array}{c}\text { Frequency } \\
\left(\mathrm{cm}^{-1}\right)\end{array}$} & \multicolumn{2}{c||}{$P_{\text {Ring }}$} & \multicolumn{2}{|c|}{ Raman ratio } \\
ring 1 & ring 2 & ring 1 & ring 2 \\
\hline 602 & 1.47 & 1.74 & 0.29 & 0.55 \\
609 & 0.98 & 6.24 & -0.09 & 0.98 \\
639 & 5.52 & 1.43 & 0.99 & -0.62 \\
596 & 0.62 & 1.08 & 0.42 & 0.38 \\
\hline
\end{tabular}

Sample C

\begin{tabular}{|c||c||c|}
\hline $\begin{array}{c}\text { Frequency } \\
\left(\mathrm{cm}^{-1}\right)\end{array}$ & $\begin{array}{c}P_{\text {Ring }} \\
\text { ring 1 }\end{array}$ & $\begin{array}{c}\text { Raman ratio } \\
\text { ring 1 }\end{array}$ \\
\hline 619 & 5.65 & 0.88 \\
652 & 1.49 & 0.78 \\
665 & 0.58 & 0.54 \\
\hline
\end{tabular}

TABLE V: Upper table: Frequency, Raman intensity and localisation entropy of the most Raman-active modes in the 490-540 $\mathrm{cm}^{-1}$ frequency range for sample $\mathrm{C} 1$ and in the $505-585 \mathrm{~cm}^{-1}$ frequency range for sample C2. Lower table: Frequency, Raman intensity and localisation entropy of the most Raman-active modes in the $605-770 \mathrm{~cm}^{-1}$ frequency range for samples $\mathrm{C} 1$ and C2.

\begin{tabular}{|c|c|c||c|c|c|}
\hline \multicolumn{3}{|c|}{ Sample C1 } & \multicolumn{3}{c|}{ Sample C2 } \\
\hline $\begin{array}{c}\text { Frequency } \\
\left(\mathrm{cm}^{-1}\right)\end{array}$ & $\begin{array}{c}\text { Raman } \\
\text { intensity (a.u. })\end{array}$ & $\begin{array}{c}\text { Localisation } \\
\text { entropy }\end{array}$ & $\begin{array}{c}\text { Frequency } \\
\left(\mathrm{cm}^{-1}\right)\end{array}$ & $\begin{array}{c}\text { Raman } \\
\text { intensity (a.u. })\end{array}$ & $\begin{array}{c}\text { Localisation } \\
\text { entropy }\end{array}$ \\
\hline 512 & $3.57 \cdot 10^{-3}$ & 0.86 & 546 & $3.42 \cdot 10^{-2}$ & 0.85 \\
503 & $6.52 \cdot 10^{-3}$ & 0.81 & 534 & $2.15 \cdot 10^{-2}$ & 0.86 \\
\hline
\end{tabular}

\begin{tabular}{|c|c|c||c|c|c|}
\hline \multicolumn{3}{|c|}{ Sample C1 } & \multicolumn{3}{c|}{ Sample C2 } \\
\hline $\begin{array}{c}\text { Frequency } \\
\left(\mathrm{cm}^{-1}\right)\end{array}$ & $\begin{array}{c}\text { Raman } \\
\text { intensity (a.u. })\end{array}$ & $\begin{array}{c}\text { Localisation } \\
\text { entropy }\end{array}$ & $\begin{array}{c}\text { Frequency } \\
\left(\mathrm{cm}^{-1}\right)\end{array}$ & $\begin{array}{c}\text { Raman } \\
\text { intensity (a.u. })\end{array}$ & $\begin{array}{c}\text { Localisation } \\
\text { entropy }\end{array}$ \\
\hline 646 & $1.54 \cdot 10^{-2}$ & 0.79 & 664 & $1.48 \cdot 10^{-2}$ & 0.79 \\
677 & $4.56 \cdot 10^{-3}$ & 0.83 & 698 & $9.65 \cdot 10^{-3}$ & 0.83 \\
632 & $2.42 \cdot 10^{-3}$ & 0.83 & 643 & $5.89 \cdot 10^{-3}$ & 0.87 \\
& & & 608 & $5.80 \cdot 10^{-3}$ & 0.80 \\
\hline
\end{tabular}


TABLE VI: $P_{\text {Ring }}$ and Raman ratio (see text for definitions) for the most Raman-active modes in the $490-540 \mathrm{~cm}^{-1}$ frequency range for sample $\mathrm{C} 1$ (upper table) and in the $505-585 \mathrm{~cm}^{-1}$ frequency range for sample C2 (lower table).

Sample C1

\begin{tabular}{|c||c|c|c|c|c|c||c|c|c|c|c|c|}
\hline $\begin{array}{c}\text { Frequency } \\
\left(\mathrm{cm}^{-1}\right)\end{array}$ & \multicolumn{4}{c||}{$P_{\text {Ring }}$} & \multicolumn{5}{c|}{ Raman ratio } \\
\hline 512 & ring 1 & ring 2 & ring 3 & ring 4 & ring 5 & ring 6 & ring 1 & ring 2 & ring 3 & ring 4 & ring 5 & ring 6 6 \\
503 & 3.15 & 1.15 & 1.43 & 1.28 & 2.22 & 0.58 & 0.30 & 0.26 & 0.30 & 0.18 & 0.27 & 0.21 \\
\hline
\end{tabular}

Sample C2

\begin{tabular}{|c|c|c|c|c|c|c|c|c|c|c|c|c|}
\hline \multirow{2}{*}{\begin{tabular}{|c|} 
Frequency \\
$\left(\mathrm{cm}^{-1}\right)$
\end{tabular}} & \multicolumn{6}{|c|}{$P_{\text {Ring }}$} & \multicolumn{6}{|c|}{ Raman ratio } \\
\hline & $n g$ & 2 & ring 3 & ring & rin & ring 6 & ng 1 & ring 2 & & 1 & & ring \\
\hline 546 & 0.78 & 0.50 & 0.88 & 1.22 & 0.73 & 1.71 & 0.20 & 0.17 & 0.19 & 0.24 & 0.03 & 0.34 \\
\hline 534 & 1.85 & 0.24 & 0.85 & 1.39 & 1.09 & 1.00 & 0.40 & $-310^{-3}$ & 0.22 & 0.13 & 0.23 & 0.24 \\
\hline
\end{tabular}

TABLE VII: $P_{\text {Ring }}$ and Raman ratio (see text for definitions) for the most Raman-active modes in the 605-770 frequency range for samples C1 (upper table) and C2 (lower table).

Sample C1

\begin{tabular}{|c||c||c|}
\hline $\begin{array}{c}\text { Frequency } \\
\left(\mathrm{cm}^{-1}\right)\end{array}$ & $\begin{array}{c}P_{\text {Ring }} \\
\text { ring 1 }\end{array}$ & $\begin{array}{c}\text { Raman ratio } \\
\text { ring 1 }\end{array}$ \\
\hline 646 & 4.83 & 0.85 \\
677 & 1.13 & 0.48 \\
632 & 1.18 & 0.72 \\
\hline
\end{tabular}

Sample C2

\begin{tabular}{|c||c||c|}
\hline $\begin{array}{c}\text { Frequency } \\
\left(\mathrm{cm}^{-1}\right)\end{array}$ & $\begin{array}{c}P_{\text {Ring }} \\
\text { ring 1 }\end{array}$ & $\begin{array}{c}\text { Raman ratio } \\
\text { ring 1 }\end{array}$ \\
\hline 664 & 3.53 & 0.79 \\
698 & 0.65 & -0.21 \\
643 & 0.98 & 0.41 \\
608 & 1.13 & 0.51 \\
\hline
\end{tabular}




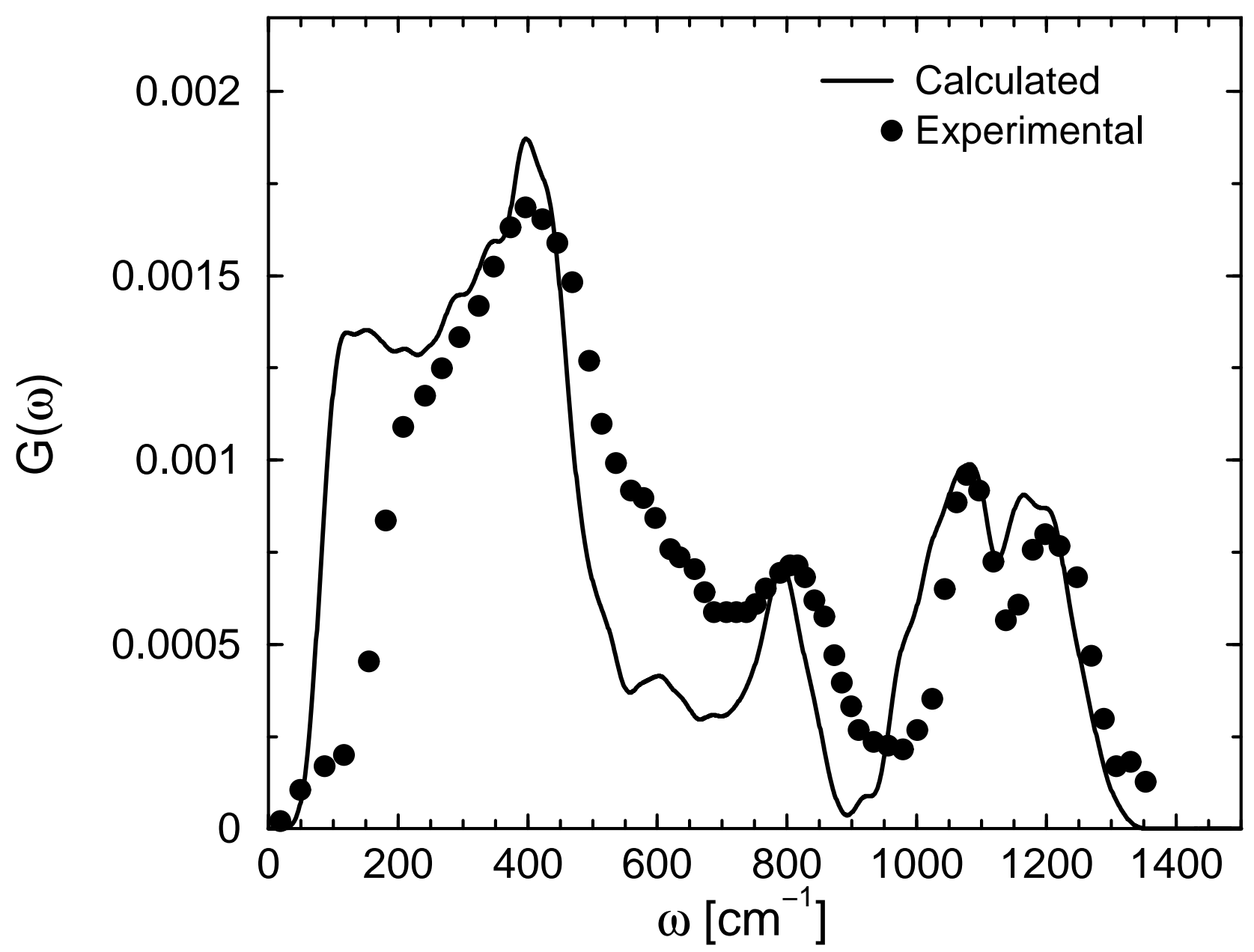

FIG. 1: Frequency dependence of the effective density of states $G(\omega)$ obtained from $a b$ initio (solid line) simulations and compared to neutron scattering experiments from Ref ${ }^{23}$ (filled circles). The calculated $G(\omega)$ has been obtained using the experimental values for the neutron scattering length factors $b_{S i}=4.149 \mathrm{fm}$ and $b_{O}=5.803 \mathrm{fm}$ and a Gaussian broadening of width $2 \sigma=35 \mathrm{~cm}^{-1}$. 


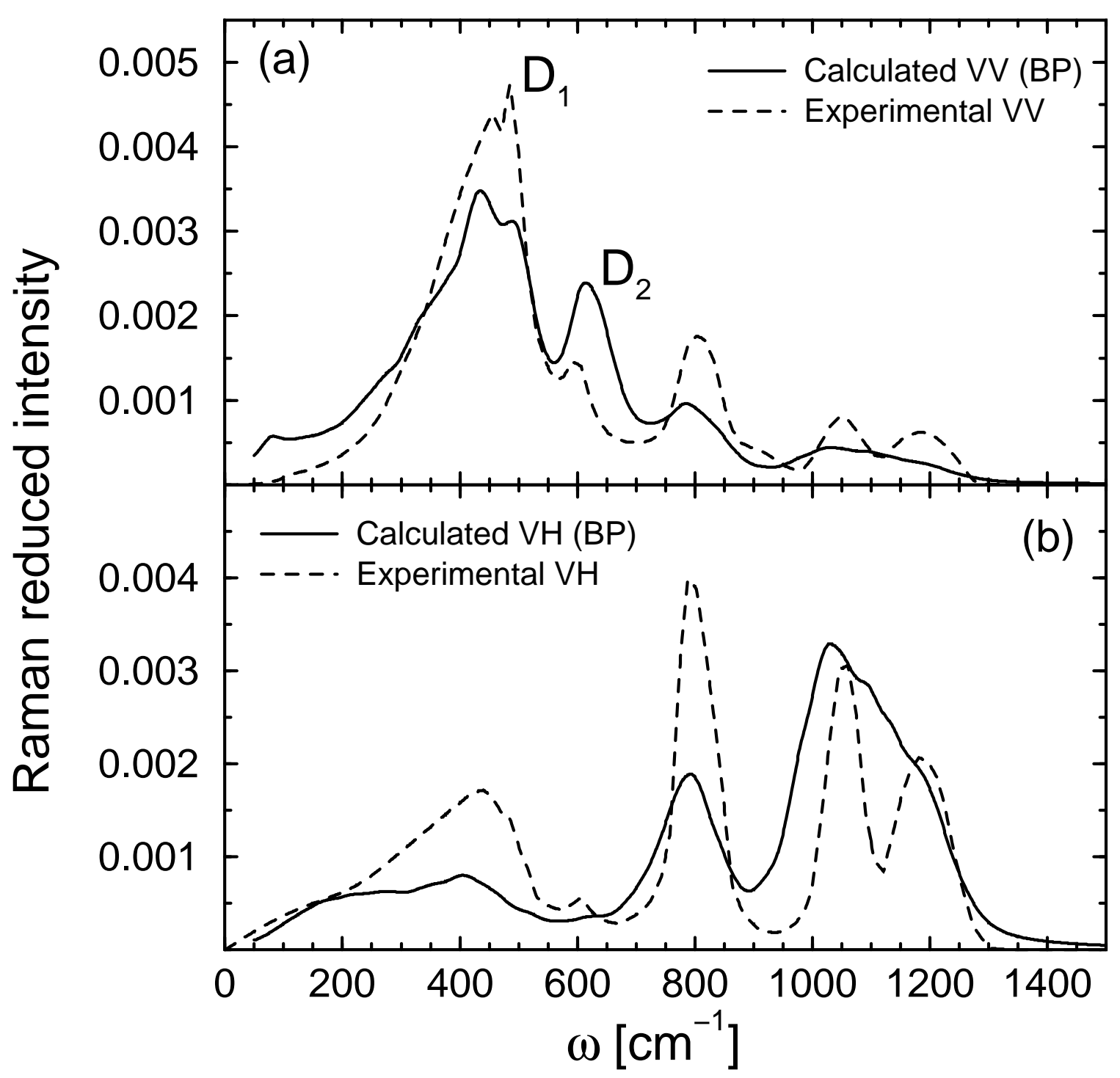

FIG. 2: (a): Frequency dependence of the VV Raman intensity calculated using the ab initio eigen modes and the bond polarizability model (solid line). The dashed line is the experimental spectrum from Ref. ${ }^{2}$. (b): Frequency dependence of the VH Raman intensity calculated using the ab initio eigen modes and the bond polarizability model (solid line). The dashed line is the experimental spectrum from Ref $\stackrel{2}{2}$. The calculated and experimental spectra have been normalized to the same total area. In the calculated spectra, the line shape is assumed to be Lorentzian and the line width is fixed to $25 \mathrm{~cm}^{-1}$. 


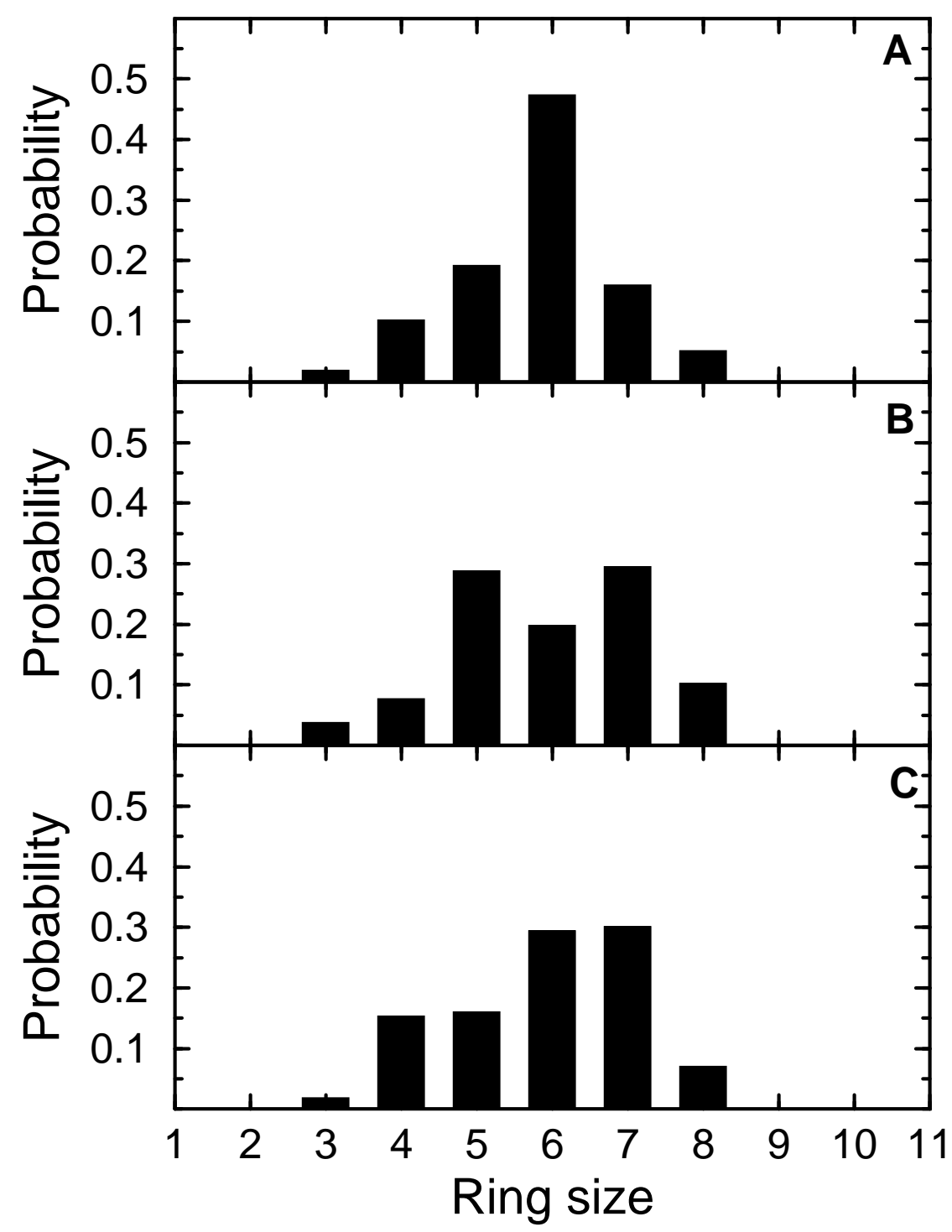

FIG. 3: Distribution of the rings size in the three amorphous silica samples A, B and C. 


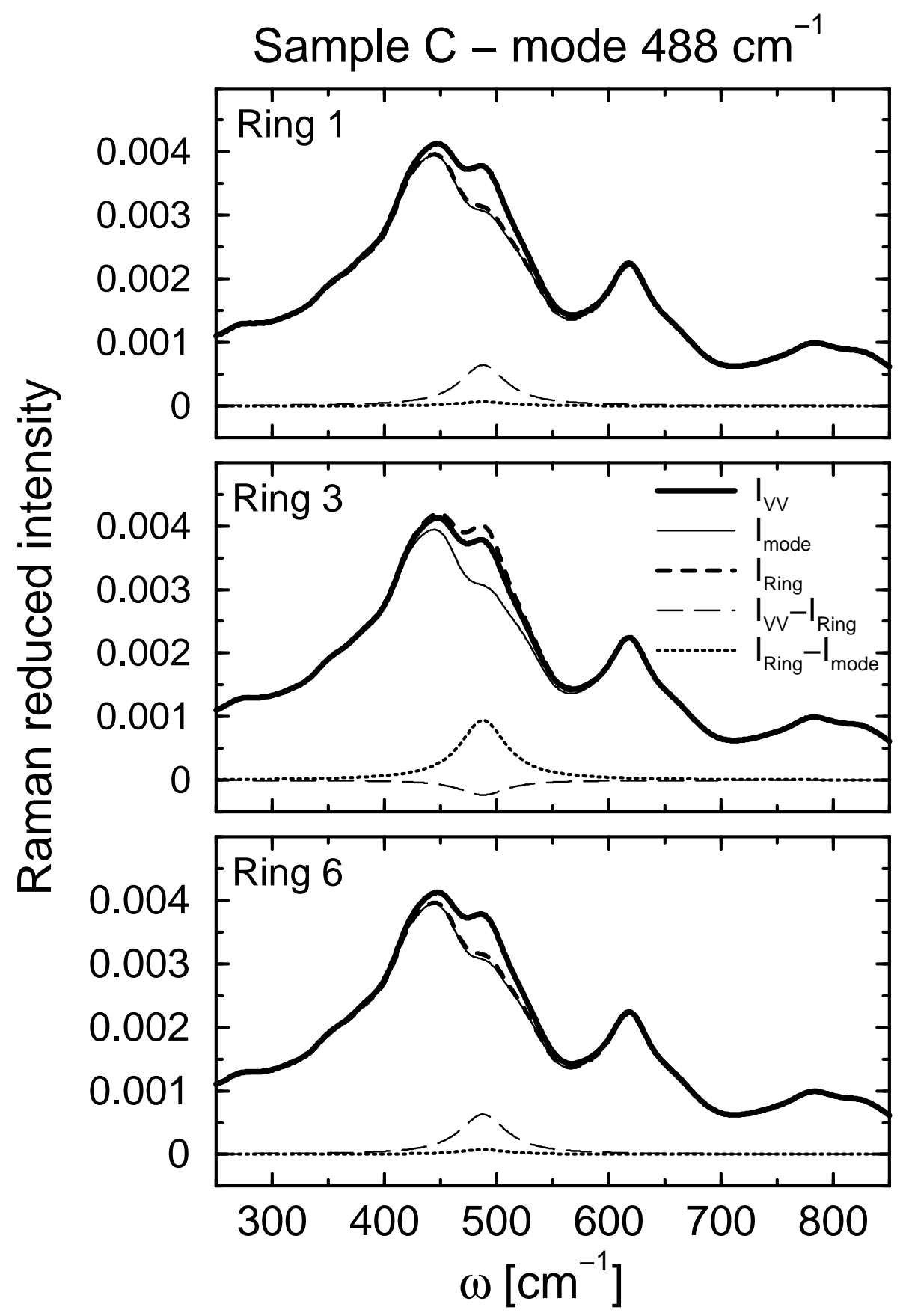

FIG. 4: $\mathbf{I}_{V V}$ : Total VV Raman spectra of sample C (bold line). $\mathbf{I}_{\text {mode }}$ VV Raman spectra in which the $488 \mathrm{~cm}^{-1}$ mode of sample $\mathrm{C}$ has been removed (thin line). $\mathbf{I}_{\text {Ring: }} \mathrm{VV}$ Raman spectra in which the eigenmode components of atoms belonging to ring 1 (upper graph), to ring 3 (center graph) or to ring 6 (lower graph) for the $488 \mathrm{~cm}^{-1}$ mode of sample $\mathrm{C}$ have been set to zero (dashed lines). 


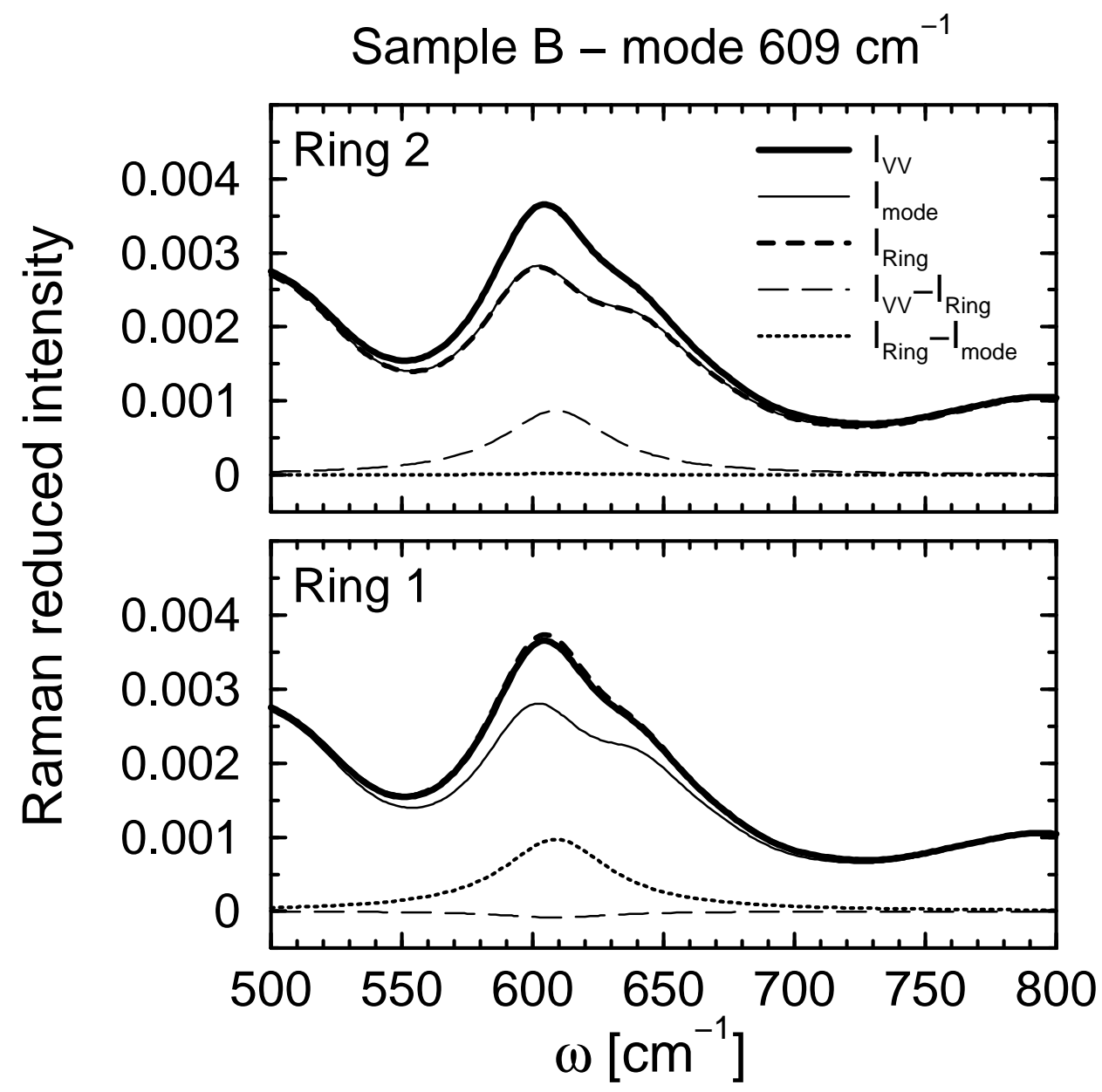

FIG. 5: $\mathbf{I}_{V V}$ : Total VV Raman spectra of sample B (bold line). $\mathbf{I}_{\text {mode }}$ VV Raman spectra in which the $609 \mathrm{~cm}^{-1}$ mode of

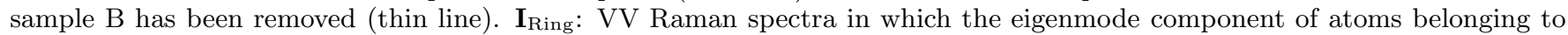
ring 2 (upper graph), or to ring 1 (lower graph) for the $609 \mathrm{~cm}^{-1}$ mode of sample B have been set to zero (dashed lines). 

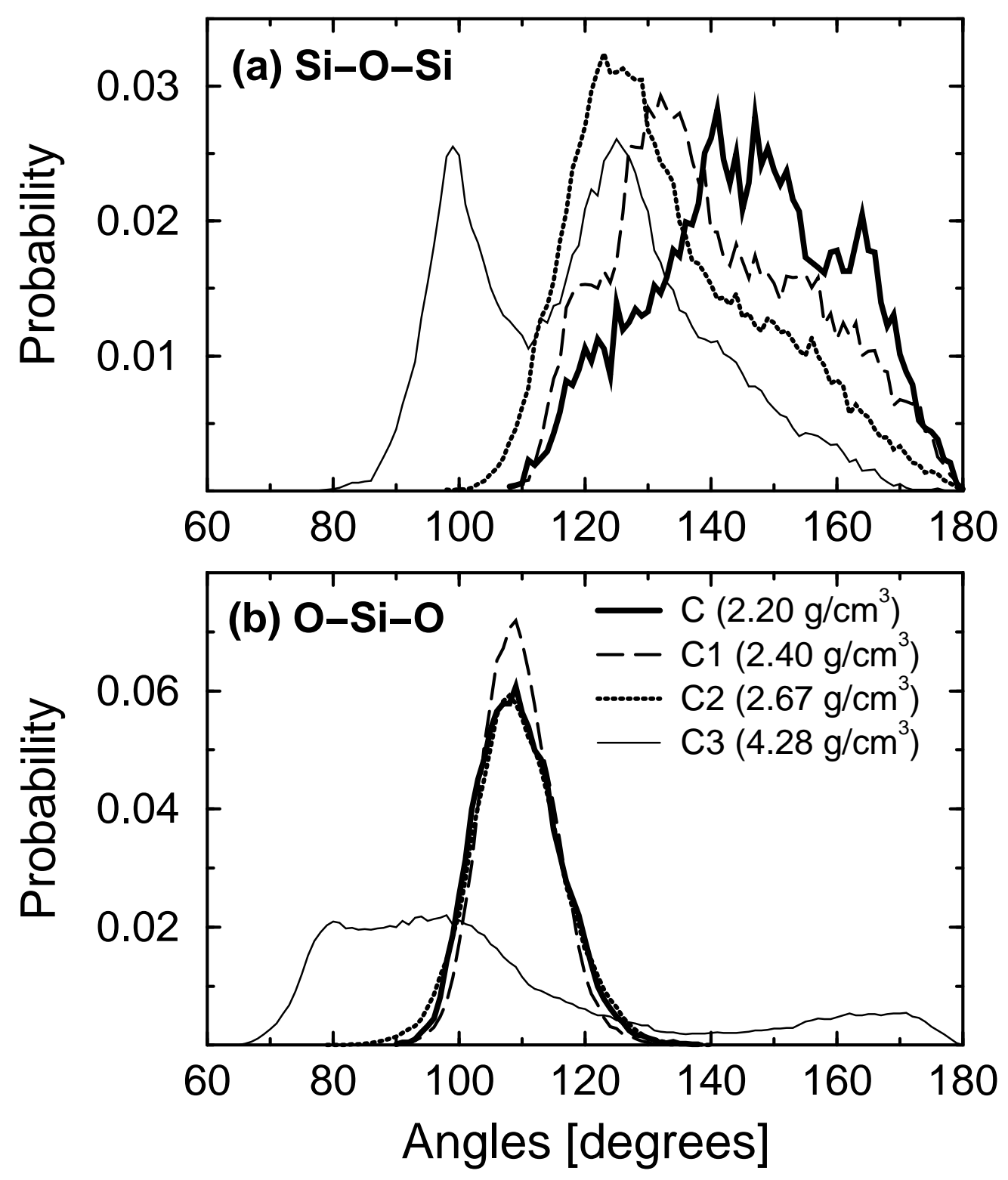

FIG. 6: Distribution of the Si-O-Si angles (a) and of the O-Si-O angles (b) of sample C at different densities: C at $2.20 \mathrm{~g} / \mathrm{cm}^{3}$ (bold line), $\mathrm{C} 1$ at $2.45 \mathrm{~g} / \mathrm{cm}^{3}$ (dashed line), C2 at $2.67 \mathrm{~g} / \mathrm{cm}^{3}$ (dotted line) and C3 at $4.28 \mathrm{~g} / \mathrm{cm}^{3}$ (solid line). 


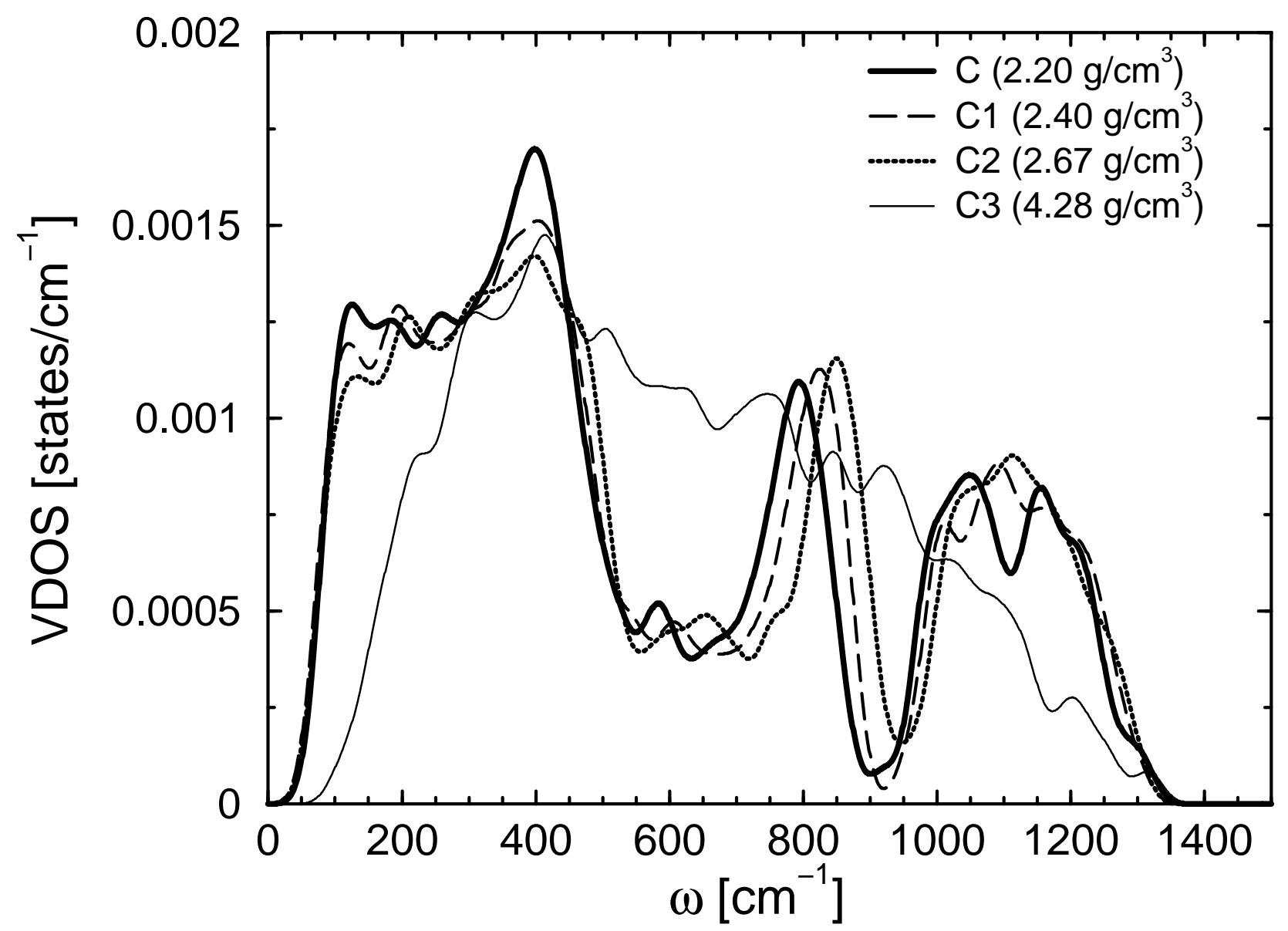

FIG. 7: Vibrational density of states of the sample $\mathrm{C}$ at different densities: $\mathrm{C}$ at $2.20 \mathrm{~g} / \mathrm{cm}^{3}$ (bold line), $\mathrm{C} 1$ at $2.45 \mathrm{~g} / \mathrm{cm}^{3}$ (dashed line), $\mathrm{C} 2$ at $2.67 \mathrm{~g} . \mathrm{cm}^{3}$ (dashed-dotted line) and $\mathrm{C} 3$ at $4.28 \mathrm{~g} / \mathrm{cm}^{3}$ (solid line). A Gaussian broadening of $2 \sigma=35$ $\mathrm{cm}^{-1}$ has been used. 

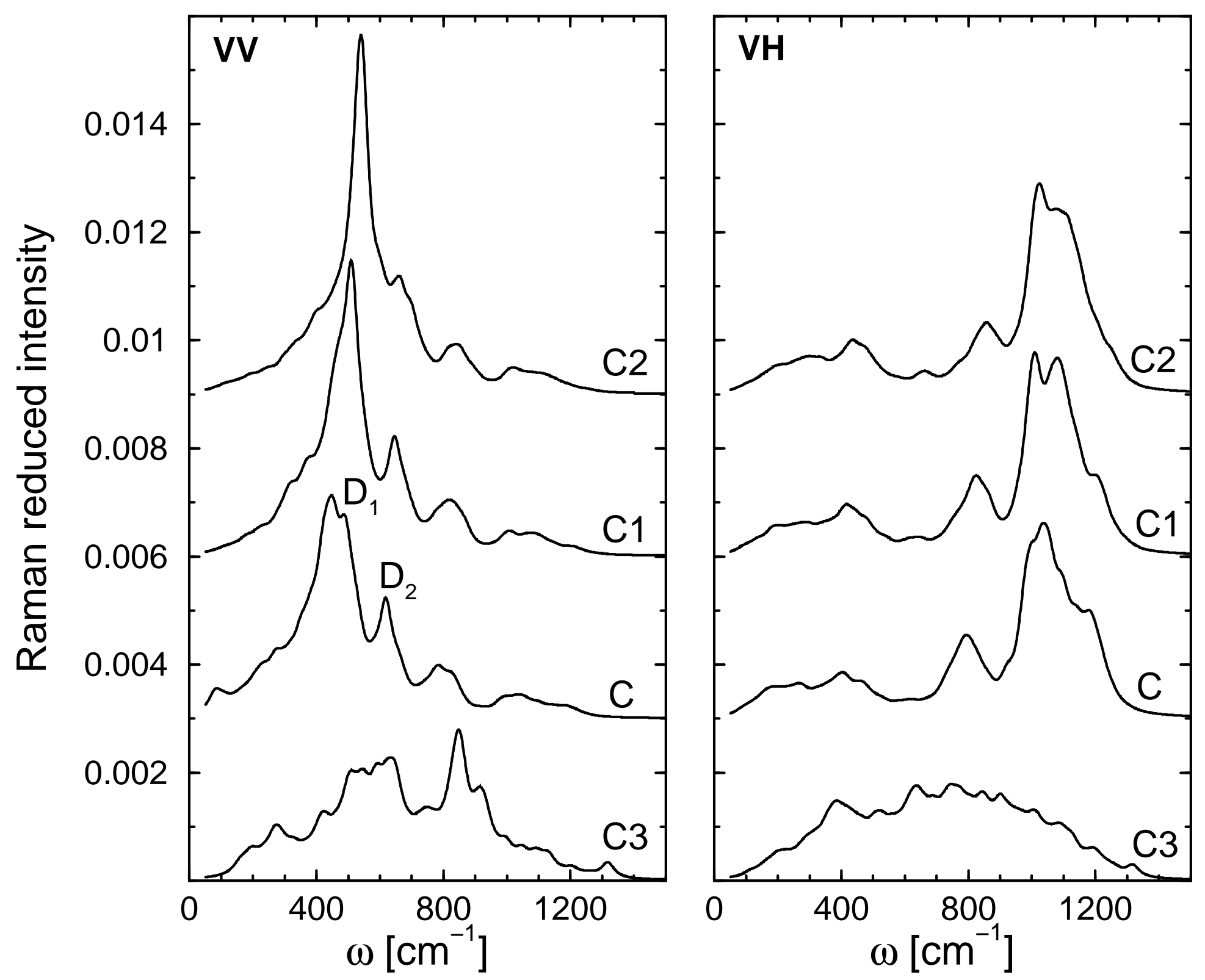

FIG. 8: Frequency dependence of the normalized VV Raman reduced intensity (left panel) and of the VH Raman intensity (right panel) for the sample $\mathrm{C}$ at different densities: $\mathrm{C}$ at $2.20 \mathrm{~g} / \mathrm{cm}^{3}, \mathrm{C} 1$ at $2.45 \mathrm{~g} / \mathrm{cm}^{3}, \mathrm{C} 2$ at $2.67 \mathrm{~g} / \mathrm{cm}^{3}$ and $\mathrm{C} 3$ at 4.28 $\mathrm{g} / \mathrm{cm}^{3}$. The spectra have been shifted vertically for clarity. 